\title{
Significant Unresolved Questions and Opportunities for Bioengineering in Understanding and Treating COVID-19 Disease Progression
}

\author{
Jasmine Shirazi, ${ }^{1}$ Michael J. Donzanti, ${ }^{1}$ Katherine M. Nelson, ${ }^{2}$ Ryan Zurakowski, ${ }^{1}$ \\ Catherine A. Fromen, ${ }^{2}$ and Jason P. Gleghorn iD ${ }^{1}$ \\ ${ }^{1}$ Department of Biomedical Engineering, University of Delaware, 161 Colburn Lab, Newark, DE 19716, USA; and ${ }^{2}$ Department \\ of Chemical and Biomolecular Engineering, University of Delaware, Newark, DE 19716, USA
}

( Received 29 May 2020; accepted 14 July 2020; published online 27 July 2020)

Associate Editor Owen McCarty oversaw the review of this article.

\begin{abstract}
COVID-19 is a disease that manifests itself in a multitude of ways across a wide range of tissues. Many factors are involved, and though impressive strides have been made in studying this novel disease in a very short time, there is still a great deal that is unknown about how the virus functions. Clinical data has been crucial for providing information on COVID-19 progression and determining risk factors. However, the mechanisms leading to the multi-tissue pathology are yet to be fully established. Although insights from SARS-CoV-1 and MERS-CoV have been valuable, it is clear that SARS-CoV-2 is different and merits its own extensive studies. In this review, we highlight unresolved questions surrounding this virus including the temporal immune dynamics, infection of non-pulmonary tissue, early life exposure, and the role of circadian rhythms. Risk factors such as sex and exposure to pollutants are also explored followed by a discussion of ways in which bioengineering approaches can be employed to help understand COVID-19. The use of sophisticated in vitro models can be employed to interrogate intercellular interactions and also to tease apart effects of the virus itself from the resulting immune response. Additionally, spatiotemporal information can be gleaned from these models to learn more about the dynamics of the virus and COVID-19 progression. Application of advanced tissue and organ system models into COVID-19 research can result in more nuanced insight into the mechanisms underlying this condition and elucidate strategies to combat its effects.
\end{abstract}

Keywords-COVID-19, ACE2, Circadian rhythms, Organotypic models, Placenta, Cytokine storm, ARDS, Host response, Immune, Sex differences.

\footnotetext{
Address correspondence to Jason P. Gleghorn, Department of Biomedical Engineering, University of Delaware, 161 Colburn Lab, Newark, DE 19716, USA. Electronic mail: gleghorn@udel.edu
}

\section{INTRODUCTION}

As SARS-CoV-2 (the virus) infection continues to spread worldwide, the scientific community is working to characterize the pathophysiology of COVID-19 (the disease) in the hopes of developing effective therapeutics to ease the burden being caused by this pandemic. Whereas insights from SARS-CoV-1 and MERS-CoV have been helpful, it has become clear that SARS$\mathrm{CoV}-2$ is more contagious and displays idiosyncrasies that separate it from the other zoonotic coronaviruses. ${ }^{33}$ Impressive strides have been made across various fields, but a great deal of information on this virus continues to elude us. With a heavy reliance on endpoint clinical data, it is difficult to determine the dynamics and timing of this dangerous infection. Infection seemingly occurs in the nasal passage and continues to spread to the lower airway, the gut, the heart, and other tissues through an unidentified route. ${ }^{39,131}$ In addition to location of spread, the timing seems to be of utmost importance. The innate and adaptive immune system work in concert to respond to this virus, and when this rhythm is disrupted, it can lead to unhampered viral spread and hyperinflammation, causing cytokine storm. ${ }^{138,192}$ The release of inflammatory cytokines at the wrong time can be the difference between mild and severe disease. Even the symptoms of COVID-19 are unpredictable and appear to abruptly change over time. Given the disease's effects on a wide range of tissues as well as its mysterious progression, there are many unresolved questions. Engineering approaches and innovative model design could aid in understanding the pathophysiology of this disease. There is an unmet need for models that allow for collection of spatiotemporal information on how the virus spreads and how the body reacts to it. In this 
perspective, we will highlight critical areas of need, such as determination of how and where the virus propagates through the body and the intricate immune response that follows, factors that could increase risk, and the ramifications of early life exposure, as well as emerging engineering tools that could address these needs.

\section{THE RESPIRATORY TRACT: SARS-COV-2 VIRAL INFECTION}

Unsurprisingly with a coronavirus, the respiratory tract is the primary focus of attention to understand pathophysiology. SARS-CoV-2, along with SARS$\mathrm{CoV}-1$, uses the transmembrane protein angiotensin converting enzyme (ACE) 2 as an entry point into cells. ${ }^{103,278}$ SARS-CoV-2 cell entry is mediated by the viral spike protein (S) binding to transmembrane ACE2 on the outer cell membrane via a receptorbinding domain (RBD). The transmembrane serine protease TMPRSS2 cleaves $\mathrm{S}$ protein enabling cell internalization by virus-plasma membrane fusion. ${ }^{103,206}$ Investigation of scRNA-seq datasets from the Human Cell Atlas Consortium showed that TMPRSS2 is more broadly expressed throughout the body compared to ACE2, suggesting that ACE2 expression is the limiting factor for viral entry. ${ }^{221} \mathrm{In}$ deed, ACE2 is expressed in alveolar epithelial type II cells along with nasal epithelial cells. ${ }^{221}$ The nasal epithelium was found to express more ACE2 compared to the lower airway epithelium, and in vitro experiments based on infecting primary cultures with recombinant SARS-CoV-2 showed an infection gradient that favored the upper airways. ${ }^{106}$ The same study found that infected nasal epithelial cells displayed more robust viral replication compared to large airway epithelial cells. ${ }^{106}$

In severe cases, COVID-19 appears to result in acute respiratory distress syndrome (ARDS), which is caused by widespread pulmonary inflammation. ${ }^{208,258}$ ARDS, which is commonly caused by sepsis and pneumonia, is characterized by pulmonary capillary permeability and neutrophil invasion, causing an acute inflammatory response along with edema. ${ }^{93}$ However, COVID-19 patients appear to present with an atypical form of ARDS with relatively high respiratory system compliance, indicating preserved lung gas volume, and low shunt fraction, while displaying severe hypoxemia. ${ }^{87}$

\section{Temporal Immune Dynamics in COVID-19}

As with any viral infection, a sophisticated immune response is critical in resolving disease and hindering the propagation of damage. Immune kinetics in suc- cessful responses are fine-tuned, and the temporal control of events ensures the balance of the inflammatory state is maintained. Similar to many airborne viruses, SARS-CoV-2 infects the pulmonary epithelium, initiating the first stage in the immune response. Inflammatory cytokines, such as interferons and interleukin (IL) -6 , are released by infected epithelial cells to recruit innate immune intervention. ${ }^{137}$ At this stage, tissue resident macrophages in the lung parenchyma and leukocytes from the blood arrive at the site of infection. Through a variety of mechanisms, this leg of the response is designed to clear extracellular virus and viral debris, minimizing the burden in the lung. At the same time, tissue resident dendritic cells capture viral antigens and migrate to nearby lymph nodes. It is here in the lymph node that antigen presentation is performed to activate $\mathrm{T}$ and $\mathrm{B}$ lymphocytes, initiating the adaptive immune response. ${ }^{215}$ This phase of the response is much more specific and targeted, as infected cells are destroyed, and the production of antibodies aids in obstruction of virus and labeling of virus for further processing and disposal by immune cells. ${ }^{62}$ While the adaptive immune response is incredibly robust and efficient in responding to pathogens, the main cost of this specificity is the time required to develop the response. It is paramount that during this transient period of priming the adaptive immunity that the innate immune response sufficiently holds off progression of the infection. For this reason, timing and coordination of the response can be one of the most crucial factors in disease outcome. Early clinical findings indicate that SARS-CoV-2 actively avoids some of these early innate immune mechanisms and can dysregulate proper timing of the response. ${ }^{63,73}$ This disruption of the response and delayed resolution has been shown to lead to a hyperinflammatory state in COVID-19 patients and can result in cytokine storm, or hypercytokinemia, and ARDS. ${ }^{110,143}$

Although data on SARS-CoV-2 has been limited and will likely be more readily available in the coming months, its similarity to SARS-CoV-1 and MERS$\mathrm{CoV}, 80$ and $50 \%$ RNA homology respectively, provides a place to start in the investigation of these immune evasion mechanisms. ${ }^{150}$ One such mechanism characterized in SARS-CoV-1 and believed to be involved in SARS-CoV-2, is the suppression of the type 1 interferon (T1IFN) response. ${ }^{73,192}$ Typically, the presence of viral RNA is discovered by pathogen recognition receptors (PRRs), such as toll-like receptors (TLRs), on the cell membrane or inside endosomes and retinoic-acid inducible gene I (RIG-I)-like receptors in the cytoplasm (RLRs). ${ }^{135,148}$ In SARSCoV-1, these important signaling receptors are suppressed, which prevents the nuclear translocation and activation of NF- $\kappa \mathrm{B}$ and IRF3. Both of these tran- 
scription factors are involved in the expression of major pro-inflammatory cytokines such as TIIFN, IL1, IL-6, and TNF- $\alpha{ }^{145,192}$ By evading immune recognition transiently after infection, the innate immunity is delayed, and the finely tuned timing of the response is disrupted. In SARS-CoV-1, this pathway of immune evasion leads to rapid viral replication and highly correlates to poor disease outcome. It is suspected that the immune response to SARS-CoV-2 similarly involves this mechanism. ${ }^{36,121}$

In addition to immune evasion techniques that allow the virus to rapidly replicate in the lung, evidence is also emerging that the virus can directly infect or obstruct immune cells. Some early studies have shown evidence that SARS-CoV-2 is capable of infecting $\mathrm{CD} 169^{+}$macrophages within the lymph node. ${ }^{38}$ The infection of these macrophages resulted in the destruction of lymph node architecture, lymphocyte death, and upregulation of inflammatory markers such as IL-6. The removal of an effective adaptive immune response would directly contribute to a poor disease resolution, characteristic of the severe cases of COVID-19. While still early, this initial finding confirms similarities to SARS-CoV-1, which also results in monocyte and macrophage infection. ${ }^{264}$ Additionally, this mechanism could contribute to the consistent findings of lymphopenia in severe COVID-19 cases. ${ }^{194}$ One COVID-19 hallmark includes depressed lymphocyte counts and a high neutrophil-lymphocyte ratio (NL ratio), pointing to an overactivation of nonspecific innate immune responses and/or depressed adaptive response. Thus, NL ratio is an effective tool for determining disease prognosis, and high NL ratio is a predictor of poor outcomes. ${ }^{259}$ Unfortunately, the exact mechanism of systemic lymphopenia in SARS$\mathrm{CoV}-2$ infection remains unclear with numerous outstanding hypotheses, including a weak or delayed overall adaptive response, poor lung-specific lymphocyte recruitment, $\mathrm{T}$ cell exhaustion, or triggered apoptosis following SARS-CoV-2 infection. ${ }^{6,224}$

Another hallmark of SARS-CoV-2 infection is the "cytokine storm" or hypercytokinemia. Severe cases of hypercytokinemia lead to critical conditions such as ARDS or multiple organ failure. ${ }^{7,162,230}$ In SARSCoV-1 and MERS-CoV, the delay in initial immune response at the beginning of infection gives the virus time for uncontrolled replication. This replication is then met with the influx of activated leukocytes, specifically neutrophils and inflammatory monocytes, that contribute to the high NL ratio consistently observed in severe cases. ${ }^{187}$ Finally, the combination of increased presence of virus and innate immune cells at the site of infection results in the high expression of T1IFN, IL-1, IL-6, and TNF- $\alpha .{ }^{73}$ While counterintuitive, early-stage immune evasion could potentially be the cause of the hyperinflammatory state seen in laterstage severe COVID-19 pathology ${ }^{192}$ (Fig. 1). In overcorrecting for the initial sluggish response, the nonantigen-specific innate immune response is unleashed and runs unchecked, contributing to the morbidity and mortality of the disease. ${ }^{275}$ In fact, immunocompromised rhesus macaques infected with MERS-CoV displayed high viral load, yet minimal lung pathology. ${ }^{248}$ This result illustrates the significance of the immune response in patient outcome and points to a potential target for therapeutic interventions by halting the runaway producers of these pro-inflammatory cytokines. Studies on COVID-19 patients in Wuhan show increased neutrophils, decreased total lymphocytes, and increased serum IL-6 and c-reactive protein, ${ }^{278}$ which is further exaggerated in ICU patients compared to non-ICU patients. ${ }^{256}$ In addition to increased plasma IL-6 levels, increased bronchoalveolar lavage fluid (BALF) IL-6 levels are associated with poor outcomes in ARDS. ${ }^{157}$ IL-6 inhibition has emerged as an intriguing target in the fight against COVID-19. However, IL-6 KO mice displayed greater bronchoalveolar inflammation compared to wild-type mice in a model of ARDS, indicating that an approach more nuanced than simply blocking IL-6 may be needed. ${ }^{238}$ Additionally, the timing of IL-6 is critical as IL-6 is necessary for the early immune response in fighting COVID-19 and other viral infections in the early stages of infection. Low IL-6 levels in the early stages of infection could result in uncontrolled viral replication. Rather than attempting to abolish IL-6 release from macrophages, a better strategy may be to regulate it.

Another component of the hyperinflammation associated with cytokine storm are the $\mathrm{T}$ helper 17 (Th17) cells. Not only have elevated Th17 responses previously been seen in MERS and SARS patients, but COVID-19 patients also display elevated Th17 cells in their peripheral blood. ${ }^{255}$ Increased hyperactivation and concentration of proinflammatory Th17 cells were also observed in a COVID-19 case study. ${ }^{258}$ Similarly, severe $\mathrm{H} 1 \mathrm{~N} 1$ response is associated with overaction of Th17 cells. ${ }^{17}$ Th17 activity causes increased IL-17 release, and its reduction reduces mortality, inflammation, and lung damage in a murine model of influenzainduced lung injury. ${ }^{50}$ Therapies that suppress Th17 function have already been suggested as a way to combat COVID-19-associated mortality. ${ }^{255}$

Although we have much more to learn about the specifics of SARS-CoV-2, its similarity to SARS-CoV1 and MERS-CoV has allowed us to recognize connections in immunopathology. It is clear that the immune response is dysregulated, and the kinetics of this response play a major role in disease progression. Inflammatory signaling, innate immunity, and adap- 


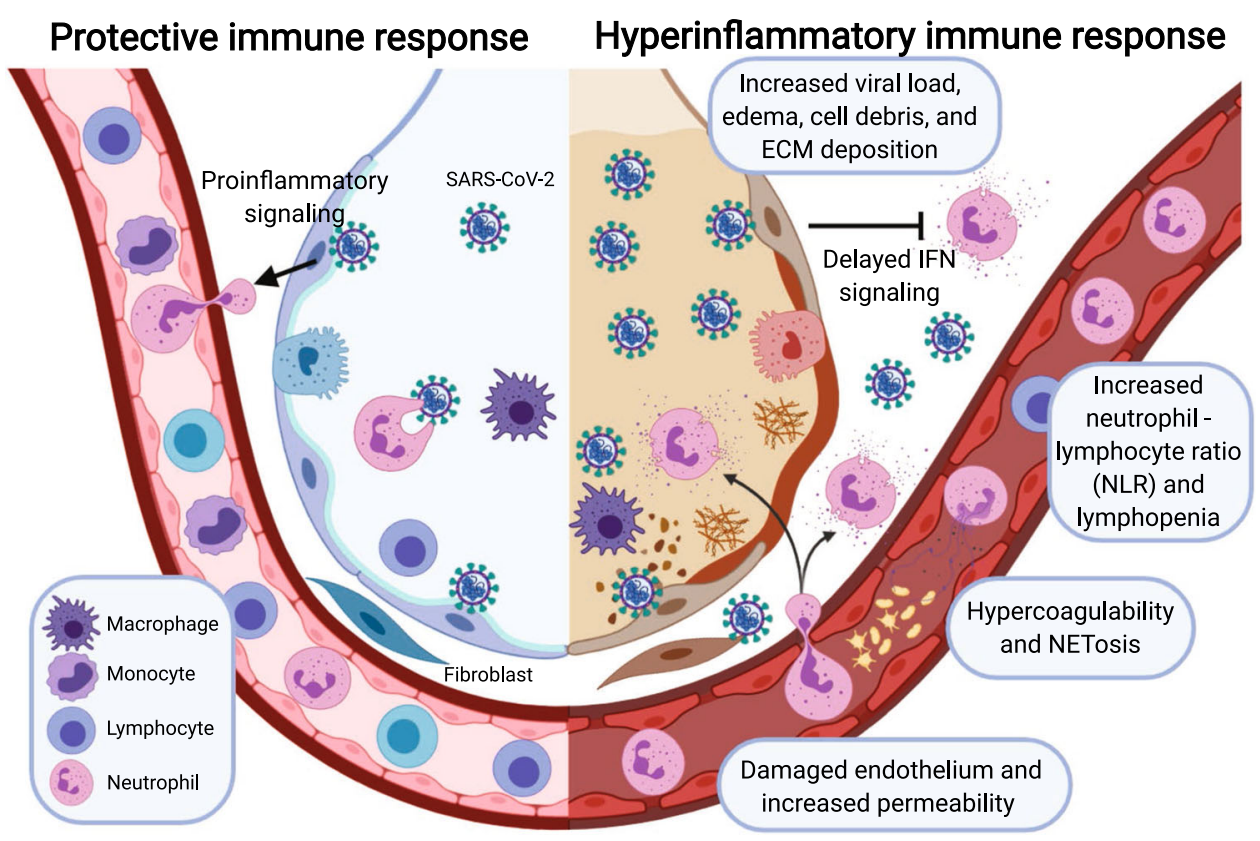

FIGURE 1. Overview of potential immune effects of SARS-CoV-2. Immune evasion, lymphopenia, and NETosis are all potential mechanisms leading to the severe immunopathology seen in patients infected with SARS-CoV-2, which includes hypercytokinemia, endothelial damage, edema, and fibrosis.

tive immunity are designed to work in unison and in a timely manner to respond to the disease. However, the potential for immune evasion mechanisms by SARSCoV-2 could point to the delayed and uncontrolled innate immune response, the poor involvement of the adaptive immune response, and the hypercytokinemia consistent with severe COVID-19 cases.

\section{ACE2/RAS CONNECTING VASCULAR/BP TO GUT AND RENAL}

To virologists, ACE2 is the SARS-CoV-2 receptor, however to physiologists, ACE2 is a vital enzyme in the renin angiotensin system (RAS), which plays a major role in maintaining blood pressure. The systemic RAS functions mainly though cleavage of one main peptide, angiotensinogen (agt), to peptides of different lengths and, therefore, different functions (Fig. 2). Importantly, an enzyme similar to ACE2, ACE, is responsible for the production of angII. AngII typically functions as a vasoconstrictive peptide, but also has pro-inflammatory and pro-fibrotic functions. ${ }^{16}$ ACE2 cleaves the vasoconstrictive peptide angII to the vasodilatory peptide ang(1-7) thereby reducing the concentration of angII and increasing the concentration of ang(1-7). The balance between ACE/ACE2 and angII/ang(1-7) is important for homeostasis and can cause disease when dysregulated. ${ }^{228,251}$ For example, ACE2 has been shown to be protective against experimentally induced fibrosis and is down-regulated in

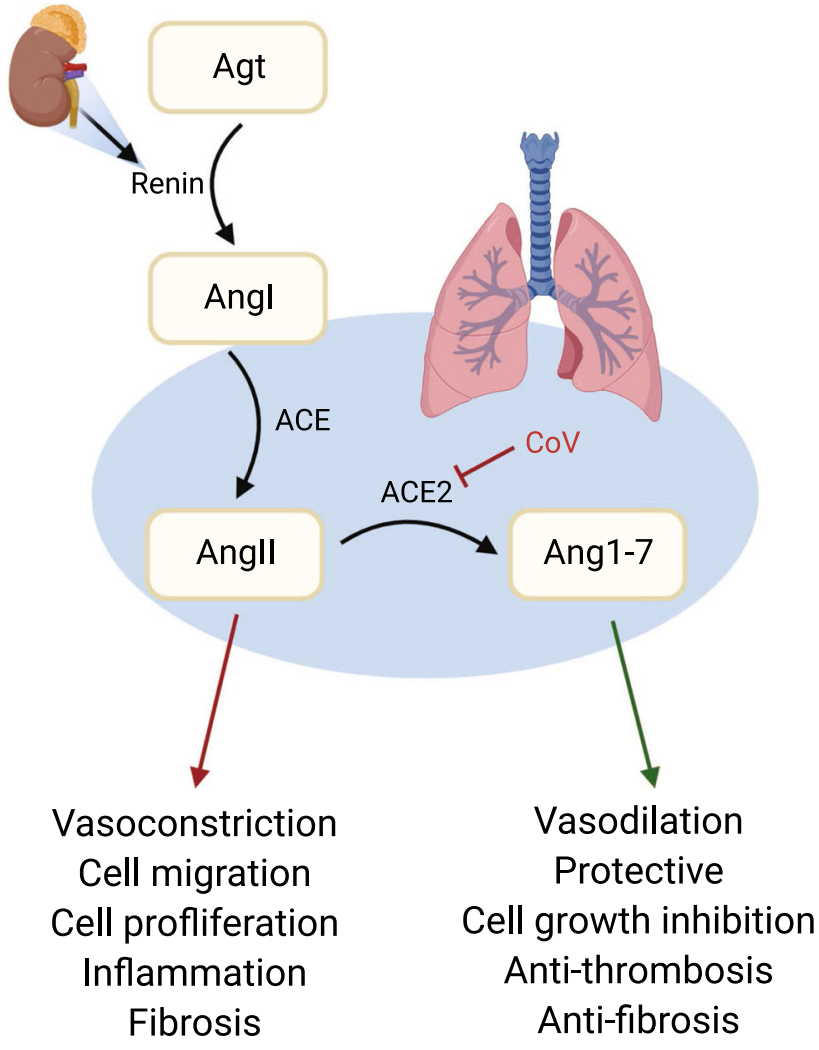

FIGURE 2. The RAS is vital for maintaining blood pressure. The RAS functions in the systemic circulation after renin is released from the kidneys. ACE2 is expressed in the pulmonary endothelium to cleave angll to protective ang(17). SARS-CoV-1, and likely SARS-CoV-2, down regulate ACE2. 
human lung fibrosis. ${ }^{139}$ Interestingly, ACE2 is downregulated by SARS-CoV-1, ${ }^{126}$ and a similar mechanism is believed to occur in SARS-CoV-2 infection as well. Downregulation of ACE2 leads to increased levels of angII ${ }^{252}$ and decreased levels of ang(1-7) which can lead to lung injury ${ }^{108,126}$ as well as cardiac and renal injury. ${ }^{174}$ However, soluble ACE2 decreased SARS-CoV-1 pseudovirion transduction in HEK cells, ${ }^{114}$ and exogenous ACE2 partially rescues lung injury in vivo. ${ }^{108}$ Therefore, the use of ACE2 as the viral entry receptor for SARS-CoV-2 may contribute to the pathology of COVID-19. ${ }^{22}$

ACE2 is generally expressed as a membrane bound protein by alveolar epithelium, vascular endothelium, and gastrointestinal epithelium. ${ }^{98,113}$ The function of ACE2 in the vascular endothelium (blood pressure maintenance ${ }^{59,229}$ ) and GI epithelium (amino acid transport $\mathrm{t}^{25}$ ) is known, while the function in the alveolar epithelium is not well characterized. However, it is at this site where SARS-CoV-2 initially enters cells to begin an infection.

Underlying conditions, specifically those related to the cardiovascular system, are large risk factors for COVID-19. However, the question remains of whether the underlying condition itself puts patients at higher risk for becoming infected or having a more severe case, or if the underlying physiology that put the patient at risk for the co-morbidity also puts the patient at risk for becoming infected with SARS-CoV-2. ACE2 has been shown to be expressed by cardiac pericytes, but not cardiomyocytes $^{39}$; however direct infection of the heart has not been common. In order for other organ systems to be infected, the virus must cross the epithelial barrier of the lung and the endothelial barrier in the capillaries to enter the blood. How this translocation occurs is unclear; however the pulmonary epithelium is damaged and leaky due to the infection, so it is not unreasonable that the virus would be able to access endothelial cells from the basal surface. Expression of ACE2 must then be present on the basal surface, which has not been established as of now. From in vitro studies, the vascular endothelium can become infected ${ }^{163}$ which has been seen to cause inflammation ${ }^{234,272}$ and impaired function of the endothelium clinically. The endothelium, specifically in the lung, highly expresses ACE2 as part of the systemic RAS. After pulmonary vascular infection, resulting dysregulation of the ACE/ACE2 and angII/ang(1-7) balance is likely. Increased angII concentrations result in lung injury and vasoconstriction leading to hypertension. Accordingly, hypertension is the most common co-morbidity with COVID-19, including a higher proportion admitted to the ICU. ${ }^{241}$

The kidney is highly involved in the RAS and regulation of blood pressure. The kidney secretes renin, the first enzyme in the RAS pathway, and regulates water content in the blood to regulate blood pressure. ACE2 is strongly expressed in the brush border of proximal tubular cells and weakly expressed in parietal epithelium and podocytes. ${ }^{98}$ There is elevated risk of acute kidney infection in COVID-19 patients, and it is associated with higher disease severity and is an adverse prognostic sign. ${ }^{41}$ As the kidney is so heavily involved in the RAS, dysregulation of the system plays a major role in kidney function. Therefore, it is not surprising that acute kidney infection is correlated with worse COVID-19 outcomes.

The other common site of initial infection, as it is also exposed to the environment, is the GI tract. ACE2 is highly expressed in the upper and stratified epithelium of the esophagus, as well as in the absorptive enterocytes of the ileum and colon. ${ }^{270}$ Clinically, symptoms of nausea and diarrhea provide evidence that many people can become infected with SARSCoV-2 within the gut. In fact, viral DNA has been found in stool ${ }^{104,225}$; however whether or not the samples are infectious has yet to be clarified. Interestingly, ACE2 expression in the gut epithelium is known to be involved in amino acid transport, not RAS regulation. ACE2 is commonly co-localized with an amino acid transporter, B0AT1. Using computer modeling, it was shown that when ACE2 is complexed with B0AT1, interaction with TMPRSS2, the cleavage enzyme necessary for viral entry, is reduced. ${ }^{207}$ B0AT1 is not commonly expressed in pulmonary epithelium, so the complexation between B0AT1 and ACE2 in the gut epithelium may be protective against infection.

There is much to be understood about the interaction and regulation between the virus and ACE2. Since SARS-CoV-1 downregulates ACE2, ${ }^{126}$ SARS-CoV-2 is expected to downregulate ACE2 as well. This downregulation is what disrupts the systemic and pulmonary RAS. However, the downregulation is thought to occur because ACE2 is internalized with the virus, meaning that only epithelial cells at the site of infection, most likely pulmonary, experience the downregulation of ACE2. Since the endogenous function of ACE2 is unknown in the pulmonary epithelium, we do not know what the downregulation does in this system. However, it is assumed that the downregulation occurs systemically as well, as that is where ACE2 functions in the RAS to reduce vasoconstriction and hypertension. How the systemic ACE2 concentration becomes reduced if most of the viral infection occurs in the epithelium is yet to be answered. There is also a question as to why ACE2 is downregulated. Why and how the virus downregulates ACE2 is important to know to understand the pathology of the infection and potentially to be able to treat the disease. In addition, ACE2 expression is known to be homeostatically regulated through many 
intra- and extra-cellular pathways which are not well understood. ${ }^{45,46,74,125,130,184,203,231}$ Correctly interpreting responses of dynamically regulated systems to perturbations is complicated by the presence of regulation, and usually requires a model-based approach. ${ }^{44}$ Animal models that can be infected by SARS-CoV-2 and show similar dysregulation in the RAS would be excellent tools to study the connection between these two factors.

\section{EARLY LIFE EXPOSURE}

Viral infection during pregnancy can result in an array of complications (reviewed in Ref. 266). The effects of SARS-CoV-2 on the fetus are unclear. It is important to consider the impact that the virus has on the mother's health and immune profile, placental function, and whether it is able to reach the developing fetus.

Vertical transmission between mother and fetus has not been demonstrated and is not a pre-requisite for maternal viral infection to cause fetal harm. ${ }^{266}$ For example, elevated maternal IL-17a release from $\mathrm{ROR} \gamma \mathrm{t}$-dependent Th17 cells is associated with greater IL-17a in the fetal brain, resulting in autism spectrum disorder-like phenotypes in offspring in a rodent model of maternal immune activation (MIA) ${ }^{43}$ This effect can be induced simply through IL-6 injection, ${ }^{212}$ suggesting that future studies on the immune response to COVID-19 in the placenta would be important.

It has not conclusively been determined whether or not the placenta can be infected with SARS-CoV-2. ${ }^{185}$ The epithelium of the placenta expresses ACE2, TMPRSS2, as well as other genes necessary for viral replication and budding. Single cell RNA-seq reveals that stromal cells, decidual perivascular cells, villous cytotrophoblasts, and syncytiotrophoblasts (STB) in the human placenta express ACE2. ${ }^{136}$ Specifically, ACE2 and TMPRSS2 are expressed by first trimester STB and second trimester extravillous trophoblasts (EVT). ${ }^{8}$ Although EVTs did not express ACE2 in early stages, ACE2 expression increased by 24 weeks gestation. ${ }^{136}$ Histological studies performed on human placenta similarly indicated ACE2 expression in the cytotrophoblasts and STB, as well as the villous blood vessel endothelium and vascular smooth muscle cells, with increased STB ACE2 expression in tissues from spontaneous miscarriages. ${ }^{232}$ ACE2 expression was also observed in the intravascular trophoblasts and decidual cells of the maternal stroma and in the umbilical cord endothelial and smooth muscle cells. ${ }^{232}$

While the effect of maternal infection has yet to have been able to be fully studied, as the virus has not been circulating in the human population longer than the gestational length of human pregnancy, it is becoming clear that the placenta is not resistant from SARS-CoV-2 infection. Placentas from women infected with SARS-CoV-2 were more likely to have histological pathologies associated, such as maternal vascular malperfusion, atherosis and fibrinoid necrosis, and hypertrophy of arterioles; ${ }^{205}$ however the placentas were not tested for SARS-CoV-2. To date, there has been no cases of vertical transmission of SARSCoV-2; however neonatal infants can contract the disease. ${ }^{4}$

The matter of whether or not vertical SARS-CoV-2 transmission occurs is controversial. ${ }^{132}$ A study performed on six SARS-CoV-2 positive pregnant women found no evidence of SARS-CoV-2 RNA in the newborns but did indicate elevated virus-specific antibodies in their sera. ${ }^{267}$ There are reports of two neonates born to SARS-CoV-2 positive mothers testing positive for SARS-CoV-2 infection based on nasopharyngeal swab. ${ }^{181}$ In these cases, the placentas displayed chronic intervillositis with macrophage infiltration, and SARSCoV-2 RNA was detected in the STB. ${ }^{181}$ Others have similarly detected SARS-CoV-2 RNA in placental samples though it was unclear whether it occurred on the maternal or fetal side, and there was no evidence of fetal infection. ${ }^{185}$ Drawing conclusions from these studies is difficult as current SARS-CoV-2 tests often suffer from poor accuracy. Apart from vertical transmission, there are questions regarding the impact of maternal COVID-19 diagnosis on gestational outcomes. One case study displayed placental abruption with acute fetal distress in a SARS-CoV-2 positive mother. ${ }^{127}$ While the link to COVID-19 is inconclusive, the patient's lack of risk factors along with to the relative rarity of this phenomenon led the authors to recommend increased surveillance in SARS-CoV-2 positive women. In a cohort study on pregnant women with severe COVID-19, 75\% delivered preterm with no neonatal deaths or evidence of vertical transmission. ${ }^{190}$ It is important to note that the majority of these patients were receiving treatment in the form of hydroxychloroquine or remdesivir. ${ }^{190}$ These drugs have had limited to no controlled studies regarding their safety during pregnancy; however the limited data has not shown an increased risk to fetal health. ${ }^{49,78} \mathrm{~A}$ meta-analysis confirmed elevated risk of preterm birth, preeclampsia, and perinatal death associated with COVID-19. ${ }^{57}$

Controlled studies on pregnant women with COVID-19 present ethical limitations. It is therefore important to develop models that allow for deeper insight regarding the likelihood of vertical transmission as well as mechanisms through which maternal immune response could cause harm to the developing fetus. 3D in vitro models of the placenta that capture 
the transport dynamics and infection potential at this interface throughout gestation could prove useful in determining whether the virus is capable of crossing the fetal barrier. Apart from fetal infection, it is also important to determine how maternal infection could alter placental phenotype. Trophoblast behavior, placental endothelial cell barrier function, and immune cell cytokine release are all important outputs for determining how maternal infection could possibly affect placental function. These factors also have implications for pre-term birth, which is known to be associated with inflammation and infection. There would also be great value in applying models of neuroinflammation and development to determine how COVID-19-associated cytokine profiles may cause changes in the developing brain.

\section{EXACERBANTS}

\section{Circadian Rhythms and Potential Chronotherapeutics}

One intriguing component of this disease is its cyclic nature. Anecdotal reports of patients feeling well during the day and taking a turn for the worse at night are common. This is not surprising as pulmonary illnesses such as ARDS and chronic obstructive pulmonary disease (COPD) have long been understood to follow circadian rhythms. ${ }^{220}$ Infectious diseases, such as influenza A or bacterial infection, are known to disrupt these circadian rhythms. Greater circadian disruption is associated with poor outcomes following viral infection. ${ }^{156} \mathrm{~A}$ shift in the circadian patterns could cause a discordance across tissues and exacerbate disease state, especially given the importance of these rhythms in the immune system. The importance of understanding the influence of circadian rhythms becomes especially apparent when one considers the fact that over a third of medical workers displayed symptoms of insomnia during the COVID-19 outbreak in China. ${ }^{274}$ Furthermore, in addition to existing vulnerable shift workers, shelter-in-place orders may result in labor rearrangements that cause an increase in circadian rhythm sleep-wake disorders in the work force. $^{112}$

Circadian rhythms largely rely on fluctuations in a collection of transcription factors. Disruptions to these fluctuations can strengthen or weaken immune function. Interestingly, macrophages are able maintain circadian rhythms ex vivo. In fact, $\sim 8 \%$ of the macrophage transcriptome displays circadian oscillations, including parts of the TLR4/TNF $\alpha$ pathway. ${ }^{119}$ Similarly, expression of TLR9, which plays an important role in viral recognition, fluctuates throughout the day, and the time of infection impacts disease severity in a murine model of sepsis. ${ }^{210}$ Modulation of circadian rhythms has long been appreciated as a method of regulating the immune response. Melatonin, a molecule that is strongly associated with regulating sleep cycles, has been suggested as a possible adjuvant treatment for COVID-19 due to its anti-inflammatory and anti-oxidation qualities. ${ }^{273}$ Bmall is an important transcription factor that maintains circadian rhythms and exerts anti-inflammatory effects, and Bmall knock out mouse models display enhanced viral infection and viral load, ${ }^{154}$ as well as increased reactive oxygen species accumulation and IL- $1 \mathrm{~b}$ release. ${ }^{67}$ Circadian rhythms are also important in lymph node biology because they modulate promigratory factor expression, resulting in oscillations in lymphocyte activity with homing peaking at night and egress peaking during the day. ${ }^{61}$ Healthy lung function also displays circadian rhythms, with peak performance midday and relatively decreased performance early morning. ${ }^{13,220}$ Interestingly, ARDS survivors display high incidences of disturbed sleep patterns following hospital discharge, and chronotherapy (in which a drug is administered at the optimal time based on circadian rhythms) has been recommended as a method to offset this phenomenon and improve patients' quality of life. ${ }^{261}$ ACE2 expression also displays circadian rhythms in some tissues, ${ }^{101}$ indicating that similar patterns may occur in the airway and that the virus's ability to enter cells may vary throughout the day.

REV-ERB $\alpha$ and $\operatorname{ROR} \gamma$ are counteracting nuclear receptors that stabilize the oscillations of circadian rhythms. ${ }^{69}$ They both act as transcription co-factors that control the expression of other circadian genes as well as genes related to metabolism, immune function, and other important processes. REV-ERB $\alpha$ activity is linked to the repression of pro-inflammatory signals in macrophages, ${ }^{69}$ particularly IL- $6,{ }^{90}$ which could be important in staving off the hyperinflammation associated with cytokine storm. Interestingly, REV-ERB $\alpha$ activity is associated with decreased IL-6 release in LPS-challenged alveolar macrophages. ${ }^{90}$ Furthermore, high tidal volume mechanical ventilation decreases REV-ERB $\alpha$ mRNA and protein in rats, ${ }^{142}$ suggesting a mechanism through which standard end-stage COVID-19 treatment could exacerbate inflammation. In fact, REV-ERB $\alpha$ agonism reduced ventilator induced lung injury-associated edema and inflammation in the same model.

ROR $\gamma$ activity is crucial for Th17 differentiation and activity, ${ }^{214}$ and others have already suggested the use of ROR $\gamma$ inhibitors for COVID-19 treatment in the hopes of suppressing excessive Th17 activity. ${ }^{255}$ 
PPAR $\gamma$ has been found to repress $\operatorname{ROR} \gamma$ in models of autoimmunity in the CNS, resulting in decreased Th17 differentiation. ${ }^{124}$ PPAR $\gamma$ is generally considered to be anti-inflammatory and has also been suggested as a potential target for COVID-19 treatment ${ }^{28,68}$ as its anti-inflammatory actions may lessen the severity of the disease. PPAR $\gamma$ also displays circadian rhythms, and its activation results in increased REV-ERB $\alpha$ transcription and decreased ROR $\gamma$ transcription. ${ }^{40,77}$

Given that both immune and pulmonary function are highly cyclical, it is important to consider temporal fluctuations in any in vitro or in vivo model. Targets such as REV-ERB $\alpha, \operatorname{ROR} \gamma, \mathrm{Bmal1}$, and Per 2 could reveal interesting infection patterns. Detecting any type of phase shift in viral replication and the immune response could be important in fighting this disease. Establishing a zeitgeber into experiments and incorporating greater temporal resolution would aid in understanding how timing of infection impacts the course of the disease and what time of day interventions are most appropriate. Understanding how circadian rhythms impact the progression of COVID-19 could aid in the development of chronotherapeutics. ${ }^{51}$ Simply knowing what time of day is optimal for administering a therapeutic could make a difference in the body's ability to clear the virus. Maintaining a regular sleep schedule promotes healthy immune function and is a simple step that can help lower the chances of a poorly timed immune response.

\section{Pollution, Smoking, and Vaping as Environmental Exacerbants}

Particulate matter (PM) in the form of air pollution is quickly emerging as a risk factor for COVID-19 mortality. SARS patients from regions with a high or moderate air pollution index had an $84 \%$ increased risk of death compared to patients from regions with low air pollution. ${ }^{52}$ Similar trends are occurring for SARS-CoV-2 infection in Northern Italy, which is one of the most polluted areas in Europe, experiencing some of the highest lethality rates in the world. ${ }^{48} \mathrm{~A}$ study in China found that a $10 \mu \mathrm{g} / \mathrm{m}^{3}$ increase in PM was associated with $\sim 3 \%$ increase in daily confirmed cases, and a similar American study showed that an increase of $1 \mu \mathrm{g} / \mathrm{m}^{3}$ of PM resulted in an $8 \%$ increase in COVID-19 mortality. ${ }^{253,279}$ Traffic related PM has also been shown to increase ACE2 expression in both pulmonary and nasal epithelial cells in vitro. ${ }^{159}$ Independent of COVID-19, exposure to PM is heavily correlated to cardiovascular disease. ${ }^{222,233} \mathrm{PM}$ exposure causes barrier dysfunction and elevated IL-6 production in HUVEC cultures ${ }^{55}$ as well as the formation of intracellular reactive oxygen species (ROS) and eventual cellular senescence, even at relatively low levels. ${ }^{24}$ The effects of PM exposure on lung function have been widely studied in the context of both air pollution, cigarette smoke, and nanoparticles. For example, diesel exhaust particles (DEP) are readily taken up by the pulmonary epithelium, resulting in altered cytokine production leading to inflammation. ${ }^{20}$ Nanoparticle inhalation in mice results in lung inflammation through increased NF-kB, IFN $\alpha, \operatorname{IFN} \beta$, IL- $1 \beta$, and IL-6. ${ }^{146} \mathrm{PM}$ in general is associated with an increased inflammatory response, causing increased production of TNF $\alpha$ and IL-6 in LPS-challenged macrophages. ${ }^{88}$ In fact, mice treated with PM displayed a dose-dependent increase in pro-inflammatory cytokines in the lung and systemically along with greater cell infiltration into the alveoli. ${ }^{179} \mathrm{PM}$-induced cytokine production in macrophages could also cause a systemic inflammatory response with increased circulating platelets, leukocytes, and prothrombotic proteins ${ }^{102}$ further contributing to COVID-19-associated mortality. Additionally, one of the hallmarks of ARDS is increased pulmonary vascular permeability, which allows excess fluid and immune cell infiltration into the lung. ${ }^{93,128} \mathrm{PM}$ is also known to decrease vascular barrier function, ${ }^{54,55,245}$ suggesting that exposure could render COVID-19 patients more susceptible to ARDS. PM exposure likewise causes oxidative stress and inflammation in the pulmonary endothelium..$^{56,97}$

Meanwhile, exposure to PM in the form of cigarette smoke is associated with decreased REV-ERB $\alpha$ transcript in the lung tissue and dysregulated cytokine release in response to LPS challenge ${ }^{262}$ and greater inflammation and cellular senescence in REV-ERB $\alpha$ $\mathrm{KO}$ mice. ${ }^{219}$ Given that cigarette smoke is associated with greater $\mathrm{ROR} \gamma$ and IL-17 expression in a murine model of COPD, it is likely that PM exposure could play a role in Th17 hyperactivation in COVID-19. ${ }^{64}$ Interestingly, cigarette smoke and air pollution, both of which are risk factors for COVID-19 mortality, also disrupt circadian rhythms, ${ }^{242}$ further suggesting a role for the dysregulation of these crucial patterns in COVID-19. E-cigarettes represent a growing public health concern, especially among youths, and they are associated with exposure to PM in the form of ultrafine particles, as well as nicotine. ${ }^{75,193}$ Even sub-chronic exposure to e-cigarettes resulted in increased macrophage and $\mathrm{T}$ cell influx into the lung along with increased inflammatory cytokine release and increased ACE2 expression. ${ }^{244}$

Exposure to PM comes with a litany of health risks (hypertension, obesity, diabetes), many of which are common co-morbidities for severe COVID-19. Recapitulating these phenotypes could aid in the development of effective therapeutics for the most vulnerable populations. Co-culture with PM-exposed immune cells or even conditioned media from PM-exposed 
immune cells could more accurately model the pathogenesis of severe cases.

\section{OUTSTANDING QUESTIONS IN PREVALENCE}

\section{Sex-Differences, Infection vs. Death Prevalence}

Trends indicate that males are more susceptible to COVID-19-associated mortality. ${ }^{257}$ Whereas the higher mortality from SARS-CoV-2 infection in men may be in part due to behavior reasons (higher risk taking, more likely to smoke, less likely to follow safety guidelines), ${ }^{18,116}$ there is also a genetic basis. ACE2 is on the X-chromosome, and ACE2 transcript expression is higher in Asian men than Asian women. ${ }^{277}$ Higher expression of ACE2 may result in a higher risk for contracting the disease. Publicly available data from China indicates that the proportion of males who succumbed to COVID-19 is 2.4 times that of females, independent of age. ${ }^{115}$ This is not particularly shocking as immune function and phenotype strongly vary between the sexes. ${ }^{176}$ For example, females have a higher proportion of $\mathrm{CD}^{+} \mathrm{T}$ cells, and males have a higher number of $\mathrm{CD}^{+}{ }^{\mathrm{T}}$ cells. ${ }^{134}$ Females also generate more activated $\mathrm{CD} 4^{+} \mathrm{T}$ cells in response to $\mathrm{T}$ cell receptor (TCR) signaling and exhibit stronger antibody responses, higher $\mathrm{B}$ cell numbers, and basal immunoglobulin levels. ${ }^{85,199}$ Generally speaking, females would appear to have more responsive immune systems. Females also have more numerous tissue resident leukocytes along with a higher density of tolllike receptors (TLRs). This is further illustrated by the fact that females are more prone to autoimmune diseases, while males are more likely to succumb to sepsis. ${ }^{176,202}$ Looking more specifically at COVID-19 pathology, it is possible that males are more prone to elevated IL-17 similar to what has been observed in males with ankylosing spondylitis, an autoimmune disorder that is associated with increased Th17 counts in males but not females. ${ }^{95}$

One possible factor in the observed differences in male and female immune systems is the transcription factor PPAR $\gamma$. Interestingly, females express more $\operatorname{PPAR} \gamma$ in their T cells. ${ }^{66,271}$ PPAR $\gamma$ acts as a negative regulator of $\mathrm{T}$ cell activation and suppresses cytokine production. ${ }^{260}$ Female PPAR $\gamma$-deficient cells display increased cytokine levels following TCR activation, but this effect is not seen in males, indicating that PPAR $\gamma$ is more important in female immunity than male immunity. PPAR $\gamma$ deficiency in female $\mathrm{T}$ cells also skews $\mathrm{T}$ cell differentiation. Interestingly, treating male $\mathrm{T}$ cells with estradiol results in greater PPAR $\gamma$ expression. ${ }^{178}$ PPAR $\gamma$ appears to have a stronger effect on inflammatory diseases in an estrogen-replete envi- ronment. These differences are also observed in the lymph node as female PPAR $\gamma$ knock out mice show increased germinal center responses, as well as increased spontaneous antibody production, whereas male mice do not. ${ }^{177}$ Interestingly, many of the immune differences observed between males and females become less pronounced if the ovaries are removed, ${ }^{202}$ indicating hormones produced and released by the ovaries, progesterone and estrogen, are driving factors in this difference.

\section{Racial/Ethnic Differences}

ACE2 expression is regulated by a variety of factors including behavioral, environmental, and genetic conditions. Asthma, COPD, hypertension, smoking, obesity, and male sex are associated with higher expression of ACE2 in bronchial biopsies, BAL, or blood samples. ${ }^{195}$ An ACE2 allele associated with higher expression is more common in the East Asian population compared to Europeans. ${ }^{27}$ Higher expression of ACE2 may result in a higher risk of contracting COVID-19, but it also may be protective of lung injury as more ACE2 is available to compensate for downregulation. Expression of ACE2 is at a lower level in the black population, which puts this group at higher risk of arterial hypertension and end organ damage. ${ }^{47}$ However, the black population in the United States is being affected by the virus at higher rates. While there are confounding factors, such as socioeconomic status, it is thought decreased expression of ACE2 may limit initial infection rates by SARS-CoV-2. However, if infection does occur, it is more severe due to physiology that is directly related to the limited ACE2 expression, like arterial hypertension. ${ }^{236}$ However, there may also be genetic factors involved for the severity of the disease as well.

\section{OPPORTUNITIES FOR BIOENGINEERS TO STUDY RESPIRATORY VIRAL LIFECYCLE}

\section{Immune System Therapeutics}

Using SARS-CoV-1 and MERS-CoV along with the stream of new clinical reports, potential therapeutic targets for COVID-19 continue to be identified. Although many antiviral therapeutics are being investigated, such as remdesivir which targets viral polymerase,${ }^{172}$ managing the host immune response is equivalently, if not more so, important. In the same way different antivirals can target a distinct point of the viral life cycle, the timing coordination of the immune system allows for targeting distinct stages in the response. 
Halting the contributions of infiltrating neutrophils and inflammatory monocytes is a clear opportunity for therapeutic intervention. One potential target could be the neutrophil extracellular traps (NETs). NETs are extracellular networks of fibers created by neutrophils, to capture and destroy pathogen. While NETs are highly protective of tissue damage during acute inflammation, they have been increasingly implicated in pathology of immune related disorders. ${ }^{175}$ From clinical data, it has been found that a higher NL ratio is seen in more severe cases and in SARS-CoV-1, increased neutrophil infiltration is associated to poor prognosis. One reason for this is the linkage between NETs and thrombosis, as many severe cases of COVID-19 show incidence of thrombosis and hypercoagulation. ${ }^{123}$ NETs can act as a thrombosis promoter, as they act as a scaffold to collect platelets and induce coagulation. ${ }^{133}$ In multiple clinical studies of COVID19, patients with severe disease state presented with elevated levels of NET remnants, such as cell-free DNA, myeloperoxidase-DNA complexes, and citrullinated histone H3. ${ }^{14,280}$ Targeting these complexes has been a major interest for potential therapeutics for SARS-CoV-2 and requires further investigation. Beyond identification of NET-specific inhibitors, halting the migration of inflammatory cells into the airspace may represent an additional approach. Previous work has demonstrated that intravenous injection of relatively inert, biocompatible nanoparticles can serve as "distractions" to otherwise migratory leukocytes, stopping their travel to sites of chronic inflammation and halting their pathological contribution. Particles with no added stimulatory or tolerizing moieties demonstrated robust anti-inflammatory preclinical responses to treat West Nile virus, inflammatory bowel disease, ${ }^{89,198}$ sepsis, ${ }^{34}$ and acute lung injury, ${ }^{80}$ driven by particle phagocytosis and subsequent cell "distraction" of inflammatory monocytes and neutrophils, respectively. This approach has shown potential for mitigating ARDS in COVID-19, ${ }^{166}$ with a multitude of other immune-engineering materials approaches currently in development.

In addition to cellular targets, modulation of humoral immunity and soluble factors has been a potential solution to COVID-19 pathology. Convalescent plasma therapy has been tested for safety and efficacy. Due to the importance of neutralizing antibodies for SARS-CoV-2 and the delayed production typically seen, a study has shown that delivering convalescent plasma from recently recovered patients was successful in improving patient outcomes. ${ }^{19}$ Clinical symptoms were improved as patients displayed increased oxyhemoglobin saturation, increased lymphocyte counts, and decreased C-reactive protein. ${ }^{65}$ This therapy has been shown to have great potential but has some logistical issues to consider, such as patient compliance in donating plasma, collecting high enough quantities to effectively treat enough patients, and determining what populations are most in need of convalescent plasma therapy. Additionally, cytokinebased interventions have been suggested as a response to hypercytokinemia. ${ }^{110}$ Drugs such as Tocilizumab, an anti-IL-6R mAb, have been successful in the blocking of IL-6 as treatment for various autoimmune disorders. ${ }^{276}$ While these therapies might have potential, the most important cytokine to target and the correct dosing need to be determined, as a full blocking of the pro-inflammatory signature could have deleterious effects.

Finally, as with many highly infectious viruses, many are looking into the development of vaccines for prophylactic protection. Possibilities for vaccines are wide ranging, including RNA/DNA vaccines, recombinant protein vaccines, vectored vaccines, inactivated vaccines, or live attenuated vaccines. ${ }^{5}$ Certainly, consideration to the route of administration may prove most valuable, with intranasal and pulmonary vaccination leading to the most robust mucosal protection for respiratory infections. ${ }^{81,149,169}$ With over 100 COVID-19 vaccines currently in development and many techniques at the disposal of vaccine developers, time remains one of the most crucial factors. Typical vaccines take many years to test for safety and efficacy, but a pandemic scenario has mandated the speeding up of this process. ${ }^{153}$ However, caution is still warranted in SARS-CoV-2 vaccine development. Evidence from prior SARS-CoV-1 vaccination studies in rhesus macaques demonstrated that generation of antibodies towards some Spike protein domains led to antibodydependent enhancement (ADE). ${ }^{144,246}$ These non-neutralizing antibodies instead promote viral uptake into host innate cells such as macrophages and monocytes through Fc-mediated receptors, leading to activation and exacerbation of their pro-inflammatory response. ${ }^{105,109}$ While such potential epitopes are being removed from most vaccine candidates, care must be taken in promoting protective and complete immune responses. ${ }^{105}$ The difficulty of promoting neutralizing antibody responses while avoiding ADE is the reason why no highly effective vaccine exists for HIV, and why most HIV vaccine candidates actually increased infection rates. ${ }^{72,282}$ So while developing a vaccine remains a major promise, the likelihood of aiding in our current pandemic status remains unclear.

\section{Molecular Pathways and Medical Dosing}

Great strides are being made in developing or reappropriating therapeutics for COVID-19, as there are many clinical trials occurring in parallel. An important 
factor that needs to be considered is dosing to maximize efficacy and minimize negative side-effects. For example, there have been multiple studies on hydroxychloroquine dosing ${ }^{86,186}$ which has proven ineffective at treating COVID-19. ${ }^{21}$ With all therapeutic clinical trials, it would be beneficial to time the administration of any drugs targeting the immune system with the natural circadian rhythms of the immune response. ${ }^{189}$ Autoimmune treatments are shown to be more effective when administered at night, ${ }^{53,92}$ and it is not unreasonable to assume that similar trends may emerge in immune-based COVID-19 treatments. Antiviral therapies should also be administered to optimize antiviral effect. ${ }^{94}$ Not much is known about optimal antiviral dosing, but circadian viral oscillations have been observed in other systems, ${ }^{71,204}$ and it is possible that there are times of day that are optimal for viral targeting. Finally, given the proven risk of cytokine storm events in COVID-19, ${ }^{110,143}$ it could be beneficial to optimize dosing and timing of vaccine administration to minimize the risk of these occurring during vaccination while also maximizing the development of a protective immune response. ${ }^{122}$

Dynamic treatment scheduling of this nature has been explored extensively in other contexts, especially in the treatment of $\mathrm{HIV}^{2,216,283}$ and cancer. ${ }^{10,151,284}$ These approaches have their roots in control theory, in which a predictive mathematical system model is updated in real-time based on measurements, and interventions are chosen to optimize the predicted behavior of the system. ${ }^{60}$ Mathematical models exist for many of the phenomena described above, including withinhost viral dynamics, ${ }^{30,31,173}$ circadian rhythms, ${ }^{11,201}$ and cytokine storm dynamics, ${ }^{79,265}$ which could easily be adapted to match COVID-19 infection behavior. Experiments will need to be designed to collect data for model tuning and validation (a process known as system identification in control theory). ${ }^{26,152,158}$ From there appropriate open-loop strategies (in which a fixed intervention schedule is applied based on measured starting conditions) and/or closed-loop strategies (in which the schedule is continually adapted based on new measurements) can be developed. ${ }^{32,239,281}$

\section{Microphysiological Systems}

COVID-19 is a complex, multifactorial disease that manifests with a broad range of pathologies, but microphysiological systems and other engineering approaches can be used to study different components of this disease (Fig. 3). For example, one feature in many COVID-19 cases is fibrosis. Some believe that the presence of fibrosis on a CT scan is good news as it indicates that healing has begun, while others claim that it is a precursor to the peak stage of the disease and could escalate into pulmonary interstitial fibrosis disease. ${ }^{263}$ It is important to understand how SARSCoV-2 infection impacts ECM generation and how any pre-existing lung injury could impact disease progression. Studying the vascular compartment is also of utmost importance as endothelial dysfunction has proven to be a crucial factor in the pathophysiology of COVID-19. ${ }^{1,227}$ There are numerous 3D in vitro models including lung-on-a-chip models that have been useful for studying the role of ECM and vasculature $^{161,164,180,209,243}$ (reviewed in Ref. 167). The incorporation of an immune component into these pulmonary models would have obvious implications for COVID-19 research, and the field is moving towards the development of such models (reviewed in Ref. 191). Being able to study how SARS-CoV-2 infection impacts lymph node activity would elucidate many of the immune phenomena that have been observed. Understanding the cytokine profile and the activity of trafficking immune cells would provide insight into the $\mathrm{T}$ cell exhaustion and other irregularities that have been observed in COVID-19 patients. The application of kidney models would also be relevant as acute kidney injury has been observed to occur with COVID-19. ${ }^{41,217}$ Kidney-on-a-chip devices have been used for drug transport and nephrotoxicity studies, ${ }^{111,140}$ and advances are reviewed in Refs. ${ }^{120}$ and ${ }^{171}$. Applying these models to COVID-19 studies could help clinicians understand how SARS-CoV-2 causes these renal pathologies and what the role of ACE2 may be. Finally, assaying COVID-19 pathology with neural models would be useful for examining long term effects of SARS-CoV-2, after the initial infection has subsided. Coronavirus infections have been shown to have deleterious effects on neurological structure and function and have the potential to lead to long term damage. Coronaviruses have been linked to diseases such as infectious toxic encephalopathy, viral encephalitis, and acute cerebrovascular disease through direct pathogen presence in the CNS, hypoxia associated with respiratory issues, or injury due to neuroinflammation. ${ }^{12,254}$ Models that can investigate the neurotropic mechanisms of the virus, hypoxia injury, and immune injury would be a critical tool for understanding the long term effects of SARS-CoV-2 and help guide therapeutic strategies to overcome them. ${ }^{99}$

For all of these models, it is important to look at samples from both sexes when studying the pathophysiology of COVID-19. Donor sex alone has been found to influence phenotype in pulmonary microvascular endothelial cells. ${ }^{268,269}$ Since hormones can heavily influence immune and lung function, it is important to account for the presence of hormones in media. ${ }^{29,223}$ Phenol red-free media is recommended for such studies because phenol red can interact with 


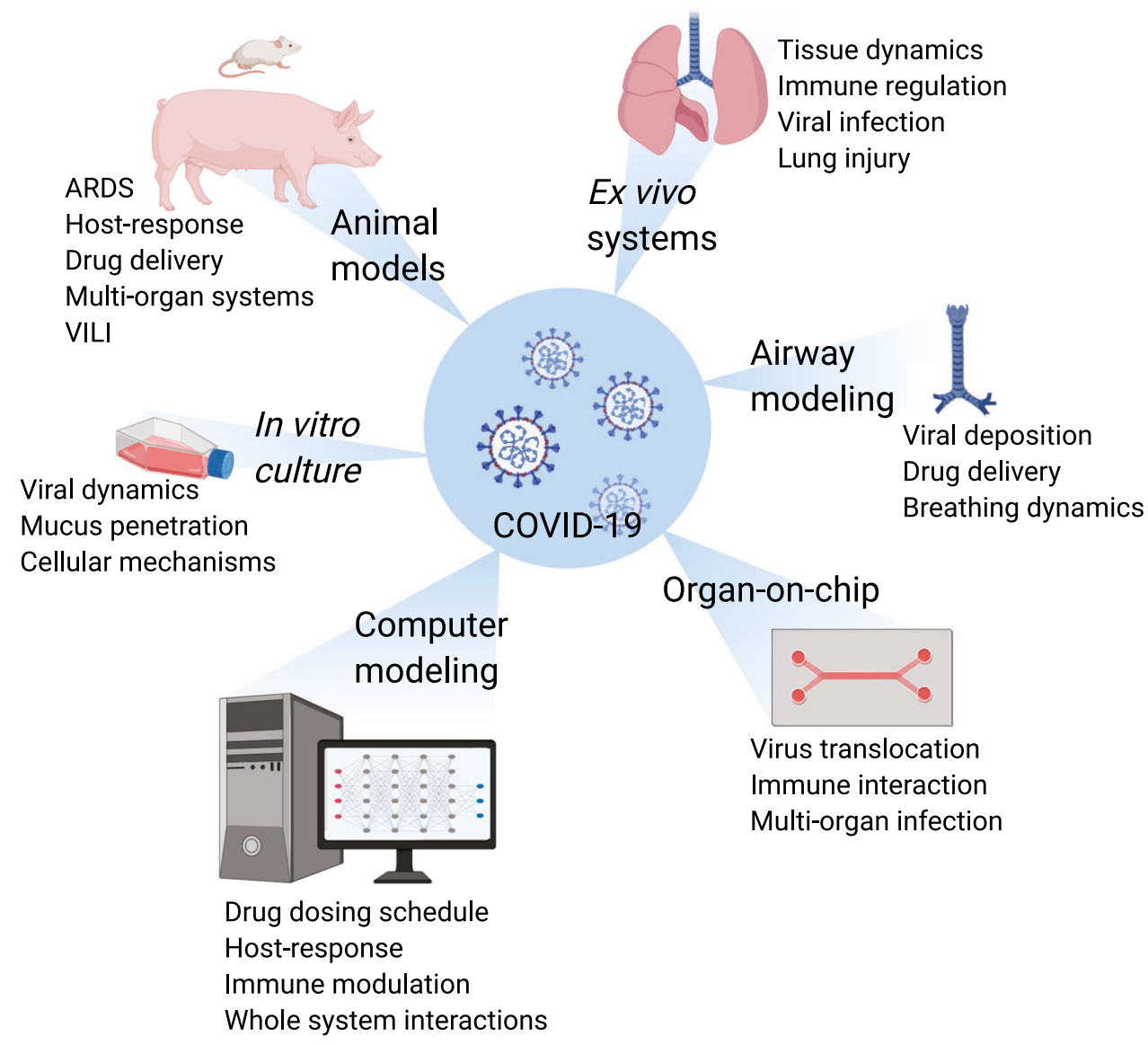

FIGURE 3. Models that could be helpful in understanding the SARS-CoV-2 infection. Examples of existing model systems may be used or novel models that could be developed to study the pathology of the infection and disease.

estrogen receptors. It is preferable to use hormone-free media and supplement hormones as desired to more closely mimic physiological conditions. Looking at cells from donors of different ethnicities is also important. Ethnic differences in pharmacokinetics have long been appreciated, ${ }^{37}$ and there have been calls to standardize reporting of observed ethnic differences in lung function. ${ }^{23}$ Given that COVID-19 is disproportionately affecting black populations in the United States, there is value in accounting for that fact in cellbased studies. Unfortunately, access to diverse cell sources can be limited, and therefore efforts should be made to obtain these resources and distribute them to research labs.

\section{Ex Vivo Culture Systems}

One potential area of exploration for bioengineers that is being underutilized, is the use of ex vivo models. While these platforms are highly complex and challenging to develop, there is a corresponding increase in control and ability to separate spatiotemporal responses, with less sacrifice of physiologic conditions.
These models are common for studying organ development $^{91,165,168,200}$ and bioreactors for organ and lung conditioning for transplant, ${ }^{96,188}$ but less common with applications to studying disease pathophysiology. This is especially critical in studying SARS-CoV-2 pathology and the progression of COVID-19. While evidence is pointing towards the shift in the immune response from protective to hyperinflammatory, there is a need to discretize this complicated spatiotemporal process, which is very difficult to achieve with patient data alone. Researchers are unable to obtain direct, realtime cell population kinetic data from human patients through the course of the infection, which will be necessary to elucidate the fundamental components of the pathology. Animal models bring our level of control closer to being able to separate and longitudinally analyze responses to viral respiratory infections, but still fail to give the necessary resolution. Therefore, models of complete lung tissue with tailorable introduction of soluble factors and immune components, could be a highly beneficial solution to this. Pathogen (pathogen associated molecular patterns, pseudovirus, or actual SARS-CoV-2) can be delivered to the airway 
epithelium, and immune constituents (damage associated molecular patterns, cytokines, and immune cells) can then be supplied at designated time points. Due to the nature of these systems, outputs can be measured in real-time via compartment sampling or live imaging to assess the kinetics of the response. Some models currently being used, such as ex vivo lung culture models and precision cut lung slices, can be adapted to study both the effects of viral infection and tissue damage, as well as the interaction between lung tissue and infiltrating immune responses. ${ }^{15,100}$ Further, development of microfluidic ex vivo lymph node models that allow observation of immune activity within the lymph node have been developed using mouse tissue. ${ }^{35,196,197}$ Advancing these approaches for comparable studies in human tissue would provide invaluable insight into viral life cycle and immune response.

\section{Preclinical Airway Models}

If the COVID-19 pandemic has illuminated one major opportunity for bioengineers, it is the opportunity to advance understanding of transport within the pulmonary system. Examples of areas in which studying transport could be beneficial include assessing the number of viral aerosols that penetrate a facemask or lead to infection, identifying the precise location of initial viral entry, determining how infection migrates downward through the respiratory tract, understanding the confounding COVID-19 hypoxia, ${ }^{87}$ and the development of inhaled therapeutics and/or vaccines. However, these studies are made difficult by the fact that the lung presents significant multi-scale, non-equilibrium transport challenges. Advancing fundamental knowledge in these areas will inform not only COVID-19 disease progression and assessment of new inhaled therapeutics, but advance understanding for a host of other respiratory diseases. Currently, there remains a lack of integrated whole lung preclinical tools or models capable of predicting how an inhaled virus will move dynamically in the lung. An optimal in vitro assessment would exactly recreate all of the anatomical features of the human lung; however, the incredible structural complexity, size, and constant motion of the airway necessitates approximations. ${ }^{155,170}$ While animal and ex vivo models can provide some insight into aspects of transport phenomena within the human respiratory tract, they do not recreate the asymmetric bifurcations of the human airway-tree needed to accurately model particulate deposition, mucocilliary transport, and localized cellular response. ${ }^{170}$ Preclinical pulmonary models that consider these multi-scale transport challenges are currently de-coupled, with experimental and computational approaches independently advancing understanding of aerosol transport through static upper and lower airspaces, particulate transport penetrating through mucosal interfaces, or cellular response in lung tissue mimics or alveolar, air-liquid-interface (ALI) microfluidic models. ${ }^{3,76,84,107,155,183,213,218,226,235,237}$ An outstanding opportunity in the field is to integrate these approaches under physiological breathing conditions. Integrated whole-lung models that incorporate airway structure, breathing maneuvers, and a mucocilliary escalator are still on the horizon, but will provide valuable insight to pathogen and host cell dynamics within the lung.

\section{Mucus}

The role of mucus in COVID-19 pathology needs to be addressed. One autopsy report indicated the presence of high viscosity gelatinous mucus in the bronchi, which could explain the dry cough observed in COVID-19 patients. ${ }^{263}$ Increased mucus secretion along with an imbalance in surface liquid volume can cause mucus to become more elastic, making it difficult to clear. $^{70,129}$ Indeed, aberrant MUC5B secretion was observed in the alveolar region in COVID-19 autopsy samples. ${ }^{106}$ Being able to model these alterations in mucus would be valuable both for understanding how SARS-CoV-2 causes the dysregulation of mucus production in the epithelium and for understanding transport dynamics with regard to virus secretion and possible uptake of inhaled therapeutics. Mucin based hydrogels have proven to be an attractive option for modeling the mechanical properties of mucus. ${ }^{117}$ The presence and qualities of mucus are known to impact diffusion of inhaled therapeutic agents. For example, inflammation can reduce the residence time of Fab' fragments, but PEGylation of these fragments results in prolonged residence time in both inflamed and healthy lungs. ${ }^{182}$ Thus, it is important to consider the mechanical properties and mucin-balance of COVID19-associated mucus when performing drug delivery studies aimed at the airway. ${ }^{147}$ Understanding alterations in the airway surface liquid as well as any changes in mucin expression is important with regard to lung function and mucociliary transport (reviewed in Ref. 9). Another concern is aerosolization of mucus as this could impact healthcare workers by exposing them to the virus during intubation, endoscopic surgery, and tracheotomies. ${ }^{240}$ Modeling the likelihood and extent of mucus aerosolization could underlie strategies to minimize transmission and has clear public health benefits.

\section{Ventilation/ARDS Models}

Another group of models with excellent utility in studying the complete life cycle of COVID-19 are ventilator models or models capable of examining the 
development of ARDS. Much of the research will be focused on the early stages of disease progression; however these later stage models can be valuable in addressing severe disease outcomes and identifying therapeutic targets. Whereas ventilator-induced lung injury (VILI) has been well studied, there is still no other option for COVID-19 patients with severe respiratory issues. ${ }^{211}$ Clinical reports show approximately $5-15 \%$ of patients infected with SARS-CoV-2 require a ventilator and intensive care observation. ${ }^{160}$ There are a variety of in vivo and ex vivo models that have been used to study VILI, and their adaptation to COVID-19 studies can help provide information as to how these severe cases and pathologies are made worse by ventilation. ${ }^{42,249}$ In addition to VILI, SARS-CoV-2 has been shown to lead to edema, fibrosis, and ARDS. Although the definition for ARDS is broad and can be applied to many diseases, interestingly, clinical data has shown that COVID-19 presents in a very specific form of ARDS ${ }^{87}$ This highlights the need for models that mimic the specific pathophysiology seen in COVID-19 as a way to identify therapeutic targets. One main challenge is the lack of ARDS models currently in use, as a murine ARDS model does not exist. This points toward a potential for model development in larger animal models or synthetic approaches that more appropriately represent human disease. There are a number of swine models capable of reproducing ARDS immunopathology being seen in COVID-19 patients, and further development of these models will help researchers in understanding SARS-CoV-2 infection. These approaches will have major implications on discovering and testing therapeutics for this virus but can broadly be applied to a number of ARDS inducing conditions such as pulmonary infections, sepsis, contact with toxic materials, and physical injury. ${ }^{7}$ Additionally, more advanced models can be used to allow direct comparisons between clinical outcomes observed in patients and the ARDS model to improve the transition of therapeutics and treatment strategies into clinical trials.

\section{CONCLUSIONS}

COVID-19 simultaneously affects multiple tissues in ways that we are only beginning to understand. Clinical samples have been enormously helpful in providing information that aids in characterizing the disease, but performing controlled experiments is still difficult. Due to animal model limitations, there is an opportunity to apply human cell-based models to SARSCoV-2 research to investigate the effects of the virus on a tissue by tissue basis with high spatiotemporal resolution. An added benefit is the ability to perform controlled experiments that are impossible in a clinical setting. The ability to study the SARS-CoV-2-induced cytokine profiles in the context of different stressors would make it possible to look at specific mechanisms underlying the pathophysiology of COVID-19 to answer unresolved questions regarding viral entry, the resulting immune cascade, and the factors that determine whether the virus is cleared or if hyperinflammation occurs. Engineered models can also be used to investigate the ways in which known risk factors exacerbate disease progression at the cellular and molecular level and help dictate avenues for additional therapies for at-risk populations. A benefit of complex models over traditional in vitro models is the ability to look at intercellular interactions and to consider multiple aspects at one time. Hypercytokinemia, ARDS, and hypercoagulopathy are some of the most obvious features in COVID-19-related mortality and morbidity, and a vascularized, perfusable lung model that incorporates immune function could aid in investigating these phenomena individually or in combination with one another. Models of other tissues such as the placenta, gut, kidney, or neurons could also aid in understanding how the virus potentially infects or otherwise impacts the body apart from the lung (Fig. 4). These strategies could dissect direct effects that are caused by the virus itself from indirect effects caused by systemic inflammation. They could also determine appropriate therapies to target individual tissues to minimize dysfunction, if necessary. Questions regarding aerosol generation and deposition and mechanical properties of lung tissue and mucus would also benefit from an engineering approach. By characterizing and then controlling these phenomena to learn how the virus moves and is deposited throughout the body, we can determine the impact on disease progression and possibly how to minimize these observed effects.

There is value in investigating multiple factors and the ways in which they interact. For example, obesity and PM exposure are both independent risk factors for poor COVID-19 outcomes, ${ }^{58,118,253}$ but PM exposure can also increase risk of obesity. ${ }^{247,250}$ Furthermore, circadian disruption is associated with obesity, ${ }^{82,83}$ and PM exposure can perturb circadian rhythms. ${ }^{141,242}$ Developing strategies to investigate these factors separately and in tandem could help determine if there is a synergistic effect or if both risk factors increase vulnerability through similar mechanisms. Furthermore, PM exposure and circadian rhythm disruption could impact cytokine release, and additional studies are needed to confirm the mechanism through which this occurs and the implications for COVID-19 treatment. Models that allow for high temporal resolution and separate control of interdependent physiological and 


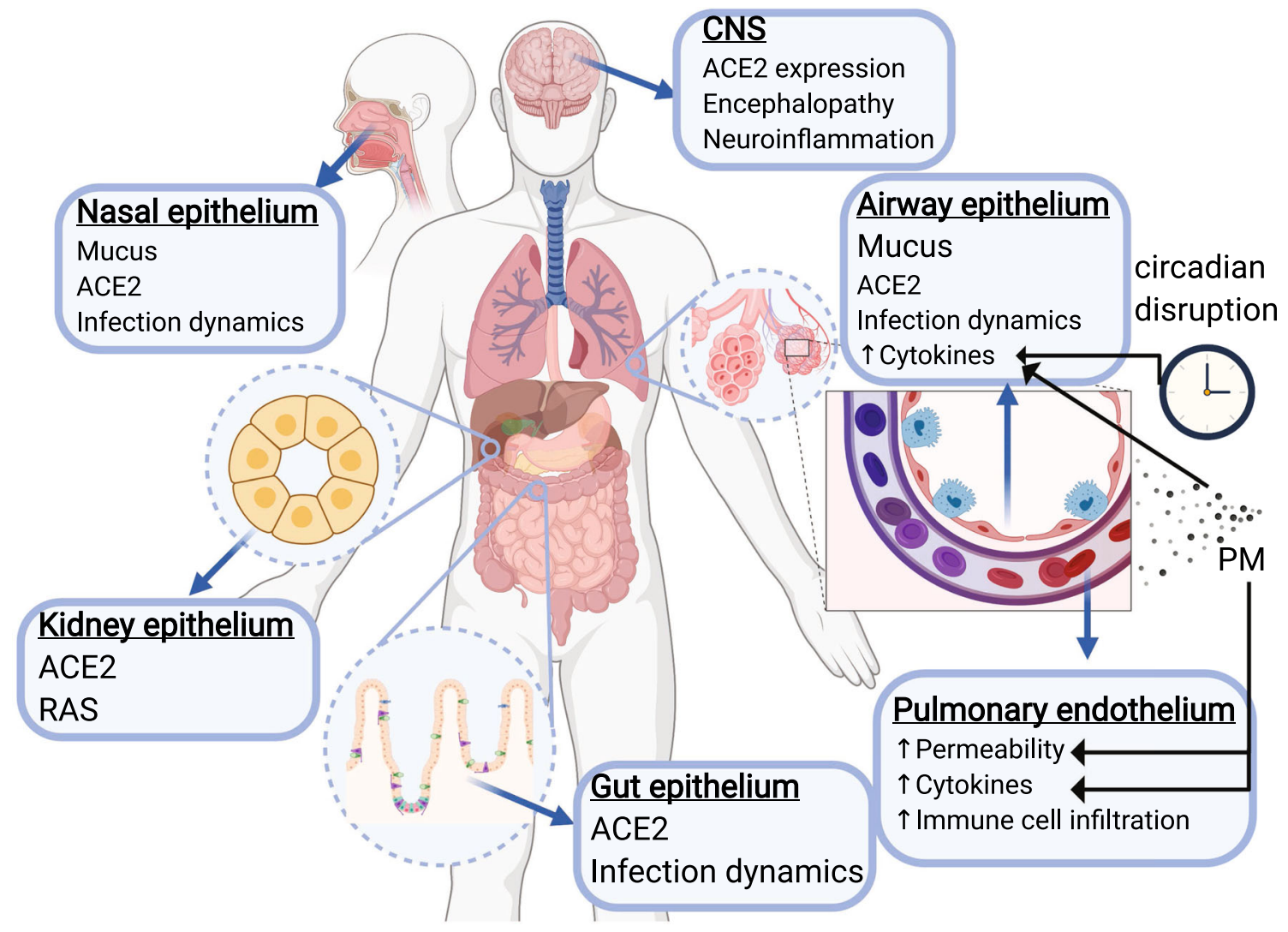

FIGURE 4. SARS-CoV-2 impacts a variety of tissues. The implementation of models to study factors such as infection dynamics, inflammation, and other factors would greatly benefit the field.

environmental factors and phenotypes would be invaluable for COVID-19 pathophysiological studies.

The impact of biomedical engineering on COVID19 research has the potential to be far-reaching, especially if partnerships and collaborations with clinicians and clinical centers are established. In addition to the repurposing of existing tools and models for COVID19 investigations, our community should endeavor to develop approaches and model systems that integrate the investigation of the complex physiological, temporal, and environmental, racial, and sex-based variables outlined herein to not only be applied to this disease but that can be applied for studies on pathogen response and lung injury more broadly. The use of engineered systems will undoubtedly accelerate the pace of COVID-19 research, bringing us closer to viable treatment strategies.

\section{ACKNOWLEDGMENTS}

This work was supported in part by grants from the National Institutes of Health [R01HL133163 (JPG), R01HL144775 (JPG), ACCEL CTR U54GM104941 (JPG, CF), R03AI136710 (RZ)], the National Science
Foundation [CBET1943686 (JPG)], and the March of Dimes Basil O'Connor Award [5-FY16-33 (JPG)]. Figures were created using Biorender.com.

\section{CONFLICT OF INTEREST}

The authors declare that they have no conflict of interest.

\section{HUMAN AND ANIMAL STUDIES}

No human studies were carried out by the authors for this article. No animal studies were carried out by the authors for this article.

\section{REFERENCES}

${ }^{1}$ Ackermann, M., S. E. Verleden, M. Kuehnel, A. Haverich, T. Welte, F. Laenger, A. Vanstapel, C. Werlein, H. Stark, A. Tzankov, W. W. Li, V. W. Li, S. J. Mentzer, and D. Jonigk. Pulmonary vascular endothelialitis, thrombosis, and angiogenesis in Covid-19. N. Engl. J. Med. 383:120-128, 2020 . 
${ }^{2}$ Adams, B. M., H. T. Banks, M. Davidian, H.-D. Kwon, H. T. Tran, S. N. Wynne, and E. S. Rosenberg. HIV dynamics: modeling, data analysis, and optimal treatment protocols. J. Comput. Appl. Math. 184:10-49, 2005.

${ }^{3}$ Ali, M., M. K. Mazumder, and T. B. Martonen. Measurements of electrodynamic effects on the deposition of MDI and DPI aerosols in a replica cast of human oralpharyngeal-laryngeal airways. J. Aerosol. Med. Pulm. Drug. Deliv. 22:35-44, 2009.

${ }^{4}$ Alzamora, M. C., T. Paredes, D. Caceres, C. M. Webb, L. M. Valdez, and M. La Rosa. Severe COVID-19 during pregnancy and possible vertical transmission. Am. J. Perinatol. 2020. https://doi.org/10.1055/s-0040-1710050.

${ }^{5}$ Amanat, F., and F. Krammer. SARS-CoV-2 vaccines: status report. Immunity 52:583-589, 2020.

${ }^{6}$ Anft, M., K. Paniskaki, A. Blazquez-Navarro, A. A. N. Doevelaar, F. Seibert, B. Hoelzer, S. Skrzypczyk, E. Kohut, J. Kurek, J. Zapka, P. Wehler, S. Kaliszczyk, S. Bajda, C. Thieme, T. Roch, M. J. Konik, T. Brenner, C. Tempfer, C. Watzl, S. Dolff, U. Dittmer, T. Westhoff, O. Witzke, U. Stervbo, and N. Babel. COVID-19 progression is potentially driven by $\mathrm{T}$ cell immunopathogenesis. Allergy Immunol. 2020. https://doi.org/10.1101/2020.04.2 8.20083089.

${ }^{7}$ ARDS Definition Task Force, V. M. Ranieri, G. D. Rubenfeld, B. T. Thompson, N. D. Ferguson, E. Caldwell, E. Fan, L. Camporota, and A. S. Slutsky. Acute respiratory distress syndrome: the Berlin Definition. JAMA 307:2526-2533, 2012

${ }^{8}$ Ashray, N., A. Bhide, P. Chakarborty, S. Colaco, A. Mishra, K. Chhabria, M. K. Jolly, and D. Modi. Singlecell RNA-seq identifies cell subsets in human placenta that highly expresses factors to drive pathogenesis of SARS-CoV-2. Cell Dev. Biol. 2020. https://doi.org/10.20 944/preprints202005.0195.v1.

${ }^{9}$ Atanasova, K. R., and L. R. Reznikov. Strategies for measuring airway mucus and mucins. Respir. Res. 20:261, 2019.

${ }^{10}$ Bagheri, N., M. Shiina, D. A. Lauffenburger, and W. M. Korn. A dynamical systems model for combinatorial cancer therapy enhances oncolytic adenovirus efficacy by MEK-inhibition. PLoS Comput. Biol. 7:e1001085, 2011.

${ }^{11}$ Bagheri, N., J. Stelling, and F. J. D. Iii. Circadian phase resetting via single and multiple control targets. PLoS Comput. Biol. 4:e1000104, 2008.

${ }^{12}$ Baig, A. M., A. Khaleeq, U. Ali, and H. Syeda. Evidence of the COVID-19 virus targeting the CNS: tissue distribution, host-virus interaction, and proposed neurotropic mechanisms. ACS Chem. Neurosci. 11:995-998, 2020.

${ }^{13}$ Barnes, P. J. Circadian variation in airway function. Am. J. Med. 79:5-9, 1985.

${ }^{14}$ Barnes, B. J., J. M. Adrover, A. Baxter-Stoltzfus, A. Borczuk, J. Cools-Lartigue, J. M. Crawford, J. DaßlerPlenker, P. Guerci, C. Huynh, J. S. Knight, M. Loda, M. R. Looney, F. McAllister, R. Rayes, S. Renaud, S. Rousseau, S. Salvatore, R. E. Schwartz, J. D. Spicer, C. C. Yost, A. Weber, Y. Zuo, and M. Egeblad. Targeting potential drivers of COVID-19: neutrophil extracellular traps. J. Exp. Med 2020. https://doi.org/10.1084/jem.202 00652.

${ }^{15}$ Beck-Broichsitter, M., J. Gauss, C. B. Packhaeuser, K. Lahnstein, T. Schmehl, W. Seeger, T. Kissel, and T. Gessler. Pulmonary drug delivery with aerosolizable nanoparticles in an ex vivo lung model. Int. J. Pharm. 367:169-178, 2009.
${ }^{16}$ Benigni, A., P. Cassis, and G. Remuzzi. Angiotensin II revisited: new roles in inflammation, immunology and aging. EMBO Mol. Med. 2:247-257, 2010.

${ }^{17}$ Bermejo-Martin, J. F., et al. Th1 and Th17 hypercytokinemia as early host response signature in severe pandemic influenza. Crit. Care 13:R201, 2009.

${ }^{18}$ Bertakis, K. D., R. Azari, L. J. Helms, E. J. Callahan, and J. A. Robbins. Gender differences in the utilization of health care services. J. Fam. Pract. 49:147-152, 2000.

${ }^{19}$ Bloch, E. M., S. Shoham, A. Casadevall, B. S. Sachais, B. Shaz, J. L. Winters, C. van Buskirk, B. J. Grossman, M. Joyner, J. P. Henderson, A. Pekosz, B. Lau, A. Wesolowski, L. Katz, H. Shan, P. G. Auwaerter, D. Thomas, D. J. Sullivan, N. Paneth, E. Gehrie, S. Spitalnik, E. A. Hod, L. Pollack, W. T. Nicholson, L. Pirofski, J. A. Bailey, and A. A. R. Tobian. Deployment of convalescent plasma for the prevention and treatment of COVID-19. $J$. Clin. Invest. 130:2757-2765, 2020.

${ }^{20}$ Boland, S., A. Baeza-Squiban, T. Fournier, O. Houcine, M.-C. Gendron, M. Chévrier, G. Jouvenot, A. Coste, M. Aubier, and F. Marano. Diesel exhaust particles are taken up by human airway epithelial cells in vitro and alter cytokine production. Am. J. Physiol. Lung Cell. Mol. Physiol. 276:L604-L613, 1999.

${ }^{21}$ Boulware, D. R., M. F. Pullen, A. S. Bangdiwala, K. A. Pastick, S. M. Lofgren, E. C. Okafor, C. P. Skipper, A. A. Nascene, M. R. Nicol, M. Abassi, N. W. Engen, M. P. Cheng, D. LaBar, S. A. Lother, L. J. MacKenzie, G. Drobot, N. Marten, R. Zarychanski, L. E. Kelly, I. S. Schwartz, E. G. McDonald, R. Rajasingham, T. C. Lee, and K. H. Hullsiek. A randomized trial of hydroxychloroquine as postexposure prophylaxis for Covid-19. N. Engl. J. Med. 2020. https://doi.org/10.1056/NEJMoa201 6638.

${ }^{22}$ Bourgonje, A. R., A. E. Abdulle, W. Timens, J.-L. Hillebrands, G. J. Navis, S. J. Gordijn, M. C. Bolling, G. Dijkstra, A. A. Voors, A. D. M. E. Osterhaus, P. H. J. van der Voort, D. J. Mulder, and H. van Goor. Angiotensinconverting enzyme-2 (ACE2), SARS-CoV-2 and pathophysiology of coronavirus disease, COVID-19. J. Pathol. 2019. https://doi.org/10.1002/path.5471.

${ }^{23}$ Braun, L., M. Wolfgang, and K. Dickersin. Defining race/ ethnicity and explaining difference in research studies on lung function. Eur. Respir. J. 41:1362-1370, 2013.

${ }^{24}$ Büchner, N., N. Ale-Agha, S. Jakob, U. Sydlik, K. Kunze, K. Unfried, J. Altschmied, and J. Haendeler. Unhealthy diet and ultrafine carbon black particles induce senescence and disease associated phenotypic changes. Exp. Gerontol. 48:8-16, 2013.

${ }^{25}$ Camargo, S. M. R., D. Singer, V. Makrides, K. Huggel, K. M. Pos, C. A. Wagner, K. Kuba, U. Danilczyk, F. Skovby, R. Kleta, J. M. Penninger, and F. Verrey. Tissuespecific amino acid transporter partners ACE2 and collectrin differentially interact with hartnup mutations. Gastroenterology 136:872-882.e3, 2009.

${ }^{26}$ Cannon, L., C. A. Vargas-Garcia, A. Jagarapu, M. J. Piovoso, and R. Zurakowski. HIV 2-LTR experiment design optimization. PLoS ONE 13:e0206700, 2018.

${ }^{27}$ Cao, Y., L. Li, Z. Feng, S. Wan, P. Huang, X. Sun, F. Wen, X. Huang, G. Ning, and W. Wang. Comparative genetic analysis of the novel coronavirus (2019-nCoV/ SARS-CoV-2) receptor ACE2 in different populations. Cell Discov. 6:1-4, 2020.

${ }^{28}$ Carboni, E., A. R. Carta, and E. Carboni. Can pioglitazone be potentially useful therapeutically in treating 
patients with covid-19? Med. Hypoth. 2020. https://doi. org/10.1016/j.mehy.2020.109776.

${ }^{29}$ Card, J. W., and D. C. Zeldin. Hormonal influences on lung function and response to environmental agents. Proc. Am. Thorac. Soc. 6:588-595, 2009.

${ }^{30}$ Cardozo, E. F., D. Ji, G. Lau, R. F. Schinazi, G.-F. Chen, R. M. Ribeiro, and A. S. Perelson. Disentangling the lifespans of hepatitis $\mathrm{C}$ virus-infected cells and intracellular vRNA replication-complexes during direct-acting anti-viral therapy. J. Viral Hepat. 27:261-269, 2020.

${ }^{31}$ Cardozo, E. F., R. Luo, M. J. Piovoso, and R. Zurakowski. Spatial modeling of HIV cryptic viremia and 2LTR formation during raltegravir intensification. $J$. Theor. Biol. 345:61-69, 2014.

${ }^{32}$ Cardozo, E. F., and R. Zurakowski. Robust closed-loop minimal sampling method for HIV therapy switching strategies. IEEE Trans. Biomed. Eng. 59:2227-2234, 2012.

${ }^{33}$ Cascella, M., M. Rajnik, A. Cuomo, S. C. Dulebohn, and R. Di Napoli. Features, evaluation and treatment coronavirus (COVID-19). In: StatPearls, edited by M. Cascella, M. Rajnik, A. Cuomo, S. C. Dulebohn, and R. Di Napoli. Treasure Island, FL: StatPearls Publishing, 2020.

${ }^{34}$ Casey, L. M., S. Kakade, J. T. Decker, J. A. Rose, K. Deans, L. D. Shea, and R. M. Pearson. Cargo-less nanoparticles program innate immune cell responses to toll-like receptor activation. Biomaterials 218:119333, 2019.

${ }^{35}$ Catterton, M. A., A. F. Dunn, and R. R. Pompano. Userdefined local stimulation of live tissue through a movable microfluidic port. Lab. Chip 18:2003-2012, 2018.

${ }^{36}$ Channappanavar, R., and S. Perlman. Pathogenic human coronavirus infections: causes and consequences of cytokine storm and immunopathology. Semin. Immunopathol. 39:529-539, 2017.

${ }^{37}$ Chen, M.-L. Ethnic or racial differences revisited. Clin. Pharmacokinet. 45:957-964, 2006.

${ }^{38}$ Chen, Y., Z. Feng, B. Diao, R. Wang, G. Wang, C. Wang, Y. Tan, L. Liu, C. Wang, Y. Liu, Y. Liu, Z. Yuan, L. Ren, and $\mathrm{Y}$. Wu. The novel severe acute respiratory syndrome coronavirus 2 (SARS-CoV-2) directly decimates human spleens and lymph nodes. Infect. Dis. (except HIV/AIDS) 2020. https://doi.org/10.1101/2020.03.27.20045427.

${ }^{39}$ Chen, L., X. Li, M. Chen, Y. Feng, and C. Xiong. The ACE2 expression in human heart indicates new potential mechanism of heart injury among patients infected with SARS-CoV-2. Cardiovasc. Res. 116:1097-1100, 2020.

${ }^{40}$ Chen, L., and G. Yang. PPARs integrate the mammalian clock and energy metabolism. PPAR Res. 2014. https://d oi.org/10.1155/2014/653017.

${ }^{41}$ Cheng, Y., R. Luo, K. Wang, M. Zhang, Z. Wang, L. Dong, J. Li, Y. Yao, S. Ge, and G. Xu. Kidney disease is associated with in-hospital death of patients with COVID19. Kidney Int. 97:829-838, 2020.

${ }^{42}$ Choi, W.-I., D. A. Quinn, K. M. Park, R. K. Moufarrej, B. Jafari, O. Syrkina, J. V. Bonventre, and C. A. Hales. Systemic microvascular leak in an in vivo rat model of ventilator-induced lung injury. Am. J. Respir. Crit. Care Med. 167:1627-1632, 2003.

${ }^{43}$ Choi, G. B., Y. S. Yim, H. Wong, S. Kim, H. Kim, S. V. Kim, C. A. Hoeffer, D. R. Littman, and J. R. Huh. The maternal interleukin-17a pathway in mice promotes autism-like phenotypes in offspring. Science 351:933-939, 2016.

${ }^{44}$ Chung, S.-W., C. R. Cooper, M. C. Farach-Carson, and B. A. Ogunnaike. A control engineering approach to understanding the TGF- $\beta$ paradox in cancer. J. R. Soc. Interface 9:1389-1397, 2012.

${ }^{45}$ Clarke, N. E., N. D. Belyaev, D. W. Lambert, and A. J. Turner. Epigenetic regulation of angiotensin-converting enzyme 2 (ACE2) by SIRT1 under conditions of cell energy stress. Clin. Sci. 126:507-516, 2014.

${ }^{46}$ Clarke, N. E., and A. J. Turner. Angiotensin-converting enzyme 2: the first decade. Int. J. Hypertens. 2011. http s://doi.org/10.1155/2012/307315.

${ }^{47}$ Cohall, D., N. Ojeh, C. M. Ferrario, O. P. Adams, and M. Nunez-Smith. Is hypertension in African-descent populations contributed to by an imbalance in the activities of the ACE2/Ang-(1-7)/Mas and the ACE/Ang II/AT1 axes? J. Renin. Angiotensin Aldosterone Syst. 2020. https://doi. org/10.1177/1470320320908186.

${ }^{48}$ Conticini, E., B. Frediani, and D. Caro. Can atmospheric pollution be considered a co-factor in extremely high level of SARS-CoV-2 lethality in Northern Italy? Environ. Pollut. 2020. https://doi.org/10.1016/j.envpol.2020.11446 5.

${ }^{49}$ Costedoat-Chalumeau, N., Z. Amoura, P. Duhaut, D. L. T. Huong, D. Sebbough, B. Wechsler, D. Vauthier, I. Denjoy, J.-M. Lupoglazoff, and J.-C. Piette. Safety of hydroxychloroquine in pregnant patients with connective tissue diseases: a study of one hundred thirty-three cases compared with a control group. Arthritis Rheum. 48:32073211, 2003.

${ }^{50}$ Crowe, C. R., K. Chen, D. A. Pociask, J. F. Alcorn, C. Krivich, R. I. Enelow, T. M. Ross, J. L. Witztum, and J. K. Kolls. Critical role of IL-17RA in immunopathology of influenza infection. J. Immunol. 183:5301-5310, 2009.

${ }^{51}$ Cruz, M., M. Miyazawa, and D. Gozal. Putative contributions of circadian clock and sleep in the context of SARS-CoV-2 infection. Eur. Respir. J. 2020. https://doi. org/10.1183/13993003.01023-2020.

${ }^{52}$ Cui, Y., Z.-F. Zhang, J. Froines, J. Zhao, H. Wang, S.-Z. $\mathrm{Yu}$, and R. Detels. Air pollution and case fatality of SARS in the People's Republic of China: an ecologic study. Environ. Health 2:15, 2003.

${ }^{53}$ Cutolo, M. Glucocorticoids and chronotherapy in rheumatoid arthritis. RMD Open 2:e000203, 2016.

${ }^{54}$ Dai, J., W. Chen, Y. Lin, S. Wang, X. Guo, and Q.-Q. Zhang. Exposure to concentrated ambient fine particulate matter induces vascular endothelial dysfunction via miR21. Int. J. Biol. Sci. 13:868-877, 2017.

${ }^{55}$ Dai, J., C. Sun, Z. Yao, W. Chen, L. Yu, and M. Long. Exposure to concentrated ambient fine particulate matter disrupts vascular endothelial cell barrier function via the IL-6/HIF- $1 \alpha$ signaling pathway. FEBS Open Bio 6:720728, 2016.

${ }^{56}$ Davel, A. P., M. Lemos, L. M. Pastro, S. C. Pedro, P. A. de André, C. Hebeda, S. H. Farsky, P. H. Saldiva, and L. V. Rossoni. Endothelial dysfunction in the pulmonary artery induced by concentrated fine particulate matter exposure is associated with local but not systemic inflammation. Toxicology 295:39-46, 2012.

${ }^{57}$ Di Mascio, D., A. Khalil, G. Saccone, G. Rizzo, D. Buca, M. Liberati, J. Vecchiet, L. Nappi, G. Scambia, V. Berghella, and F. D'Antonio. Outcome of coronavirus spectrum infections (SARS, MERS, COVID-19) during pregnancy: a systematic review and meta-analysis. Am. J. Obstet. Gynecol. MFM 2:100107, 2020.

${ }^{58}$ Dietz, W., and C. Santos-Burgoa. Obesity and its implications for COVID-19 mortality. Obesity 28:1005, 2020 . 
${ }^{59}$ Donoghue, M., F. Hsieh, E. Baronas, K. Godbout, M. Gosselin, N. Stagliano, M. Donovan, B. Woolf, K. Robison, R. Jeyaseelan, R. E. Breitbart, and S. Acton. A novel angiotensin-converting enzyme-related carboxypeptidase (ACE2) converts angiotensin I to angiotensin 1-9. Circulat. Res. 2000. https://doi.org/10.1161/01. res.87.5.e1.

${ }^{60}$ Doyle, F., L. Jovanovic, D. Seborg, R. S. Parker, B. W. Bequette, A. M. Jeffrey, X. Xia, I. K. Craig, and T. McAvoy. A tutorial on biomedical process control. $J$. Process Control 17:571-572, 2007.

${ }^{61}$ Druzd, D., O. Matveeva, L. Ince, U. Harrison, W. He, C. Schmal, H. Herzel, A. H. Tsang, N. Kawakami, A. Leliavski, O. Uhl, L. Yao, L. E. Sander, C.-S. Chen, K. Kraus, A. de Juan, S. M. Hergenhan, M. Ehlers, B. Koletzko, R. Haas, W. Solbach, H. Oster, and C. Scheiermann. Lymphocyte circadian clocks control lymph node trafficking and adaptive immune responses. Immunity 46:120-132, 2017.

${ }^{62}$ Du, L., Y. He, Y. Zhou, S. Liu, B.-J. Zheng, and S. Jiang. The spike protein of SARS-CoV-a target for vaccine and therapeutic development. Nat. Rev. Microbiol. 7:226-236, 2009.

${ }^{63} \mathrm{Du}$, S. Q., and W. Yuan. Mathematical modeling of interaction between innate and adaptive immune responses in COVID-19 and implications for viral pathogenesis. J. Med. Virol. 2020. https://doi.org/10.1002/ jmv. 25866 .

${ }^{64}$ Duan, M.-C., H.-J. Tang, X.-N. Zhong, and Y. Huang. Persistence of Th17/Tc17 cell expression upon smoking cessation in mice with cigarette smoke-induced emphysema. Clin. Dev. Immunol. 2013. https://doi.org/10.1155/ 2013/350727.

${ }^{65}$ Duan, K., et al. Effectiveness of convalescent plasma therapy in severe COVID-19 patients. Proc. Natl. Acad. Sci. 117:9490-9496, 2020.

${ }^{66}$ Dunn, S. E., S. S. Ousman, R. A. Sobel, L. Zuniga, S. E. Baranzini, S. Youssef, A. Crowell, J. Loh, J. Oksenberg, and L. Steinman. Peroxisome proliferator-activated receptor (PPAR)alpha expression in $\mathrm{T}$ cells mediates gender differences in development of $\mathrm{T}$ cell-mediated autoimmunity. J. Exp. Med. 204:321-330, 2007.

${ }^{67}$ Early, J. O., D. Menon, C. A. Wyse, M. P. CervantesSilva, Z. Zaslona, R. G. Carroll, E. M. Palsson-McDermott, S. Angiari, D. G. Ryan, S. E. Corcoran, G. Timmons, S. S. Geiger, D. J. Fitzpatrick, D. O'Connell, R. J. Xavier, K. Hokamp, L. A. J. O'Neill, and A. M. Curtis. Circadian clock protein BMAL1 regulates IL-1 $\beta$ in macrophages via NRF2. Proc. Natl. Acad. Sci. 115:E8460E8468, 2018.

${ }^{68}$ Erol, A. Pioglitazone treatment for the COVID-19-associated cytokine storm. OSF Preprints 2020. https://doi. org/10.31219/osf.io/avfpb.

${ }^{69}$ Everett, L. J., and M. A. Lazar. Nuclear receptor Reverb $\alpha$ : up, down, and all around. Trends Endocrinol. Metab. 25:586-592, 2014.

${ }^{70}$ Fahy, J. V., and B. F. Dickey. Airway mucus function and dysfunction. N. Engl. J. Med. 363:2233-2247, 2010.

${ }^{71}$ Fan, A., and K. Wang. A viral infection model with immune circadian rhythms. Appl. Math. Comput. 215:33693374, 2010.

${ }^{72}$ Fauci, A. S., and H. D. Marston. Toward an HIV vaccine: a scientific journey. Science 349:386-387, 2015.
${ }^{73}$ Felsenstein, S., J. A. Herbert, P. S. McNamara, and C. M. Hedrich. COVID-19: immunology and treatment options. Clin. Immunol. 215:108448, 2020.

${ }^{74}$ Fernandes, T., N. Y. Hashimoto, F. C. Magalhães, F. B. Fernandes, D. E. Casarini, A. K. Carmona, J. E. Krieger, M. I. Phillips, and E. M. Oliveira. Aerobic exercise training-induced left ventricular hypertrophy involves regulatory MicroRNAs, decreased angiotensin-converting enzyme-angiotensin ii, and synergistic regulation of angiotensin-converting enzyme 2-angiotensin (1-7). Hypertension 58:182-189, 2011.

${ }^{75}$ Fernández, E., M. Ballbè, X. Sureda, M. Fu, E. Saltó, and J. M. Martínez-Sánchez. Particulate matter from electronic cigarettes and conventional cigarettes: a systematic review and observational study. Curr. Environ. Health Reep. 2:423-429, 2015.

${ }^{76}$ Fishman, J. M., K. Wiles, M. W. Lowdell, P. De Coppi, M. J. Elliott, A. Atala, and M. A. Birchall. Airway tissue engineering: an update. Expert Opin. Biol. Ther. 14:14771491, 2014.

${ }^{77}$ Fontaine, C., G. Dubois, Y. Duguay, T. Helledie, N. VuDac, P. Gervois, F. Soncin, S. Mandrup, J.-C. Fruchart, J. Fruchart-Najib, and B. Staels. The orphan nuclear receptor Rev-Erbalpha is a peroxisome proliferator-activated receptor (PPAR) gamma target gene and promotes PPARgamma-induced adipocyte differentiation. J. Biol. Chem. 278:37672-37680, 2003.

${ }^{78}$ Food and Drug Administration. Fact Sheet for Health Care Providers Emergency Use Authorization (EUA) of Remdesivir (GS-5734 ${ }^{\mathrm{TM}}$ ). London: Food Press, 2020.

${ }^{79}$ Foteinou, P. T., S. E. Calvano, S. F. Lowry, and I. P. Androulakis. In silico simulation of corticosteroids effect on an NFkB-dependent physicochemical model of systemic inflammation. PLOS ONE 2009. https://doi.org/10. 1371/journal.pone.0004706.

${ }^{80}$ Fromen, C. A., W. J. Kelley, M. B. Fish, R. Adili, J. Noble, M. J. Hoenerhoff, M. Holinstat, and O. EniolaAdefeso. Neutrophil-particle interactions in blood circulation drive particle clearance and alter neutrophil responses in acute inflammation. ACS Nano 11:1079710807, 2017.

${ }^{81}$ Fromen, C. A., G. R. Robbins, T. W. Shen, M. P. Kai, J. P. Y. Ting, and J. M. DeSimone. Controlled analysis of nanoparticle charge on mucosal and systemic antibody responses following pulmonary immunization. Proc. Natl. Acad. Sci. 112:488-493, 2015.

${ }^{82}$ Froy, O. Metabolism and Circadian rhythms - implications for obesity. Endocr. Rev. 31:1-24, 2010.

${ }^{83}$ Froy, O. Circadian rhythms and obesity in mammals. ISRN Obes. 2012. https://doi.org/10.5402/2012/437198.

${ }^{84}$ Fulcher, M. L., S. E. Gabriel, J. C. Olsen, J. R. Tatreau, M. Gentzsch, E. Livanos, M. T. Saavedra, P. Salmon, and S. H. Randell. Novel human bronchial epithelial cell lines for cystic fibrosis research. Am. J. Physiol. Lung Cell Mol. Physiol. 296:L82-L91, 2009.

${ }^{85}$ Furman, D. Sexual dimorphism in immunity: improving our understanding of vaccine immune responses in men. Expert Rev. Vaccines 14:461-471, 2015.

${ }^{86}$ Garcia-Cremades, M., B. P. Solans, E. Hughes, J. P. Ernest, E. Wallender, F. Aweeka, A. F. Luetkemeyer, and R. M. Savic. Optimizing hydroxychloroquine dosing for patients with COVID-19: an integrative modeling approach for effective drug repurposing. Clin. Pharmacol. Ther. 2020. https://doi.org/10.1002/cpt.1856. 
${ }^{87}$ Gattinoni, L., S. Coppola, M. Cressoni, M. Busana, S. Rossi, and D. Chiumello. COVID-19 does not lead to a "typical" acute respiratory distress syndrome. Am. J. Respir. Crit. Care Med. 201:1299-1300, 2020.

${ }^{88}$ Gawda, A., G. Majka, B. Nowak, M. Śróttek, M. Walczewska, and J. Marcinkiewicz. Air particulate matter SRM 1648a primes macrophages to hyperinflammatory response after LPS stimulation. Inflamm. Res. 67:765-776, 2018.

${ }^{89}$ Getts, D. R., R. L. Terry, M. T. Getts, C. Deffrasnes, M. Müller, C. van Vreden, T. M. Ashhurst, B. Chami, D. McCarthy, H. Wu, J. Ma, A. Martin, L. D. Shae, P. Witting, G. S. Kansas, J. Kühn, W. Hafezi, I. L. Campbell, D. Reilly, J. Say, L. Brown, M. Y. White, S. J. Cordwell, S. J. Chadban, E. B. Thorp, S. Bao, S. D. Miller, and N. J. C. King. Therapeutic inflammatory monocyte modulation using immune-modifying microparticles. Sci. Transl. Med. 6:219ra7, 2014.

${ }^{90}$ Gibbs, J. E., J. Blaikley, S. Beesley, L. Matthews, K. D. Simpson, S. H. Boyce, S. N. Farrow, K. J. Else, D. Singh, D. W. Ray, and A. S. I. Loudon. The nuclear receptor REV-ERB $\alpha$ mediates circadian regulation of innate immunity through selective regulation of inflammatory cytokines. Proc. Natl. Acad. Sci. 109:582-587, 2012.

${ }^{91}$ Gilbert, R. M., J. T. Morgan, E. S. Marcin, and J. P. Gleghorn. Fluid mechanics as a driver of tissue-scale mechanical signaling in organogenesis. Curr. Pathobiol. Rep. 4:199-208, 2016.

${ }^{92}$ Glass-Marmor, L., T. Paperna, Y. Ben-Yosef, and A. Miller. Chronotherapy using corticosteroids for multiple sclerosis relapses. J. Neurol. Neurosurg. Psychiatry 78:886-888, 2007.

${ }^{93}$ Gonzales, J., R. Lucas, and A. Verin. The acute respiratory distress syndrome: mechanisms and perspective therapeutic approaches. Austin. J. Vasc. Med. 2:1009, 2015.

${ }^{94}$ Goyal, A., E. F. Cardozo-Ojeda, and J. T. Schiffer. Potency and timing of antiviral therapy as determinants of duration of SARS CoV-2 shedding and intensity of inflammatory response. medRxiv 2020. https://doi.org/10. $1101 / 2020.04 .10 .20061325$.

${ }^{95}$ Gracey, E., Y. Yao, B. Green, Z. Qaiyum, Y. Baglaenko, A. Lin, A. Anton, R. Ayearst, P. Yip, and R. D. Inman. Sexual dimorphism in the Th17 signature of ankylosing spondylitis. Arthritis Rheumatol. 68:679-689, 2016.

${ }^{96}$ Guenthart, B. A., J. D. O’Neill, J. Kim, D. Queen, S. Chicotka, K. Fung, M. Simpson, R. Donocoff, M. Salna, C. C. Marboe, K. Cunningham, S. P. Halligan, H. M. Wobma, A. E. Hozain, A. Romanov, G. Vunjak-Novakovic, and $M$. Bacchetta. Regeneration of severely damaged lungs using an interventional cross-circulation platform. Nat. Commun. 10:1985, 2019.

${ }^{97}$ Haberzettl, P., D. J. Conklin, W. T. Abplanalp, A. Bhatnagar, and T. E. O'Toole. Inhalation of fine particulate matter impairs endothelial progenitor cell function via pulmonary oxidative stress. Arterioscl. Thromb. Vasc. Biol. 38:131-142, 2018.

${ }^{98}$ Hamming, I., W. Timens, M. L. C. Bulthuis, A. T. Lely, G. J. Navis, and H. van Goor. Tissue distribution of ACE2 protein, the functional receptor for SARS coronavirus: a first step in understanding SARS pathogenesis. $J$. Pathol. 203:631-637, 2004.

${ }^{99}$ Haring, A. P., H. Sontheimer, and B. N. Johnson. Microphysiological human brain and neural systems-on- a-chip: potential alternatives to small animal models and emerging platforms for drug discovery and personalized medicine. Stem Cell Rev. Rep. 13:381-406, 2017.

${ }^{100}$ Henjakovic, M., K. Sewald, S. Switalla, D. Kaiser, M. Müller, T. Z. Veres, C. Martin, S. Uhlig, N. Krug, and A. Braun. Ex vivo testing of immune responses in precisioncut lung slices. Toxicol. Appl. Pharmacol. 231:68-76, 2008.

${ }^{101}$ Herichová, I., D. Šoltésová, K. Szántóová, B. Mravec, D. Neupauerová, A. Veselá, and M. Zeman. Effect of angiotensin II on rhythmic per2 expression in the suprachiasmatic nucleus and heart and daily rhythm of activity in Wistar rats. Regul. Pept. 186:49-56, 2013.

${ }^{102}$ Hiraiwa, K., and S. F. van Eeden. Contribution of lung macrophages to the inflammatory responses induced by exposure to air pollutants. Mediators Inflamm. 2013. http s://doi.org/10.1155/2013/619523.

${ }^{103}$ Hoffmann, M., H. Kleine-Weber, S. Schroeder, N. Krüger, T. Herrler, S. Erichsen, T. S. Schiergens, G. Herrler, N.-H. Wu, A. Nitsche, M. A. Müller, C. Drosten, and S. Pöhlmann. SARS-CoV-2 cell entry depends on ACE2 and TMPRSS 2 and is blocked by a clinically proven protease inhibitor. Cell 181:271-280.e8, 2020.

${ }^{104}$ Holshue, M. L., C. DeBolt, S. Lindquist, K. H. Lofy, J. Wiesman, H. Bruce, C. Spitters, K. Ericson, S. Wilkerson, A. Tural, G. Diaz, A. Cohn, L. Fox, A. Patel, S. I. Gerber, L. Kim, S. Tong, X. Lu, S. Lindstrom, M. A. Pallansch, W. C. Weldon, H. M. Biggs, T. M. Uyeki, and S. K. Pillai. First case of 2019 novel coronavirus in the United States. N. Engl. J. Med. 382:929-936, 2020.

${ }^{105}$ Hotez, P. J., D. B. Corry, and M. E. Bottazzi. COVID-19 vaccine design: the Janus face of immune enhancement. Nat. Rev. Immunol. 20:347-348, 2020.

${ }^{106} \mathrm{Hou}, \mathrm{Y}$. J., et al. SARS-CoV-2 reverse genetics reveals a variable infection gradient in the respiratory tract. Cell 2020. https://doi.org/10.1016/j.cell.2020.05.042.

${ }^{107}$ Huh, D., B. D. Matthews, A. Mammoto, M. MontoyaZavala, H. Y. Hsin, and D. E. Ingber. Reconstituting organ-level lung functions on a chip. Science 328:16621668, 2010.

${ }^{108}$ Imai, Y., K. Kuba, S. Rao, Y. Huan, F. Guo, B. Guan, P. Yang, R. Sarao, T. Wada, H. Leong-Poi, M. A. Crackower, A. Fukamizu, C. C. Hui, L. Hein, S. Uhlig, A. S. Slutsky, C. Jiang, and J. M. Penninger. Angiotensin-converting enzyme 2 protects from severe acute lung failure. Nature 436:112-116, 2005.

${ }^{109}$ Iwasaki, A., and Y. Yang. The potential danger of suboptimal antibody responses in COVID-19. Nat. Rev. Immunol. 20:339-341, 2020.

${ }^{110}$ Jamilloux, Y., T. Henry, A. Belot, S. Viel, M. Fauter, T. El Jammal, T. Walzer, B. François, and P. Sève. Should we stimulate or suppress immune responses in COVID-19? Cytokine and anti-cytokine interventions. Autoimmunity Rev. 2020. https://doi.org/10.1016/j.autrev.2020.102567.

${ }^{111}$ Jang, K.-J., A. P. Mehr, G. A. Hamilton, L. A. McPartlin, S. Chung, K.-Y. Suh, and D. E. Ingber. Human kidney proximal tubule-on-a-chip for drug transport and nephrotoxicity assessment. Int. Bio (Cam) 5:1119-1129, 2013.

${ }^{112}$ Jeff, B. W. Circadian rhythm sleep-wake disorders and the COVID-19 pandemic. J. Clin. Sleep Med. 2020. https://d oi.org/10.5664/jcsm. 8540 .

${ }^{113}$ Jia, H. P., D. C. Look, L. Shi, M. Hickey, L. Pewe, J. Netland, M. Farzan, C. Wohlford-Lenane, S. Perlman, and P. B. McCray. ACE2 receptor expression and severe 
acute respiratory syndrome coronavirus infection depend on differentiation of human airway epithelia. J. Virol. 79:14614-14621, 2005.

${ }^{114}$ Jia, H. P., D. C. Look, P. Tan, L. Shi, M. Hickey, L. Gakhar, M. C. Chappell, C. Wohlford-Lenane, and P. B. McCray. Ectodomain shedding of angiotensin converting enzyme 2 in human airway epithelia. Am. J. Physiol. Lung Cell. Mol. Physiol. 297:84, 2009.

${ }^{115}$ Jin, J.-M., P. Bai, W. He, F. Wu, X.-F. Liu, D.-M. Han, S. Liu, and J.-K. Yang. Gender differences in patients with COVID-19: focus on severity and mortality. Front. Public Health 2020. https://doi.org/10.3389/fpubh.2020.00152.

${ }^{116}$ Johnson, H. D., D. Sholcosky, K. Gabello, R. Ragni, and N. Ogonosky. Sex differences in public restroom handwashing behavior associated with visual behavior prompts. Percept. Mot. Skills 97:805-810, 2003.

${ }^{117}$ Joyner, K., D. Song, R. F. Hawkins, R. D. Silcott, and G. A. Duncan. A rational approach to form disulfide linked mucin hydrogels. Soft Matter 15:9632-9639, 2019.

${ }^{118}$ Kassir, R. Risk of COVID-19 for patients with obesity. Obes Rev 2020. https://doi.org/10.1111/obr.13034.

${ }^{119}$ Keller, M., J. Mazuch, U. Abraham, G. D. Eom, E. D. Herzog, H.-D. Volk, A. Kramer, and B. Maier. A circadian clock in macrophages controls inflammatory immune responses. Proc. Natl. Acad. Sci. 106:21407-21412, 2009.

${ }^{120}$ Kim, S., and S. Takayama. Organ-on-a-chip and the kidney. Kidney Res. Clin. Pract. 34:165-169, 2015.

${ }^{121}$ Kindler, E., V. Thiel, and F. Weber. Interaction of SARS and MERS coronaviruses with the antiviral interferon response. Adv. Virus Res. 96:219-243, 2016.

${ }^{122}$ Kitamura, H., C. Sedlik, A. Jacquet, B. Zaragoza, M. Dusseaux, V. Premel, X. Sastre-Garau, and O. Lantz. Long peptide vaccination can lead to lethality through CD4+ $\mathrm{T}$ cell-mediated cytokine storm. J. Immunol. 185:892-901, 2010.

${ }^{123}$ Klok, F. A., M. J. H. A. Kruip, N. J. M. van der Meer, M. S. Arbous, D. Gommers, K. M. Kant, F. H. J. Kaptein, J. van Paassen, M. A. M. Stals, M. V. Huisman, and H. Endeman. Confirmation of the high cumulative incidence of thrombotic complications in critically ill ICU patients with COVID-19: an updated analysis. Thromb. Res. 2020. https://doi.org/10.1016/j.thromres.2020.04.041.

${ }^{124}$ Klotz, L., S. Burgdorf, I. Dani, K. Saijo, J. Flossdorf, S. Hucke, J. Alferink, N. Novak, M. Beyer, G. Mayer, B. Langhans, T. Klockgether, A. Waisman, G. Eberl, J. Schultze, M. Famulok, W. Kolanus, C. Glass, C. Kurts, and P. A. Knolle. The nuclear receptor PPAR $\gamma$ selectively inhibits Th17 differentiation in a $\mathrm{T}$ cell-intrinsic fashion and suppresses CNS autoimmunity. J. Exp. Med. 206:2079-2089, 2009.

${ }^{125}$ Kuan, T.-C., T.-H. Yang, C.-H. Wen, M.-Y. Chen, I.-L. Lee, and C.-S. Lin. Identifying the regulatory element for human angiotensin-converting enzyme 2 (ACE2) expression in human cardiofibroblasts. Peptides 32:1832-1839, 2011.

${ }^{126}$ Kuba, K., Y. Imai, S. Rao, H. Gao, F. Guo, B. Guan, Y. Huan, P. Yang, Y. Zhang, W. Deng, L. Bao, B. Zhang, G. Liu, Z. Wang, M. Chappell, Y. Liu, D. Zheng, A. Leibbrandt, T. Wada, A. S. Slutsky, D. Liu, C. Qin, C. Jiang, and J. M. Penninger. A crucial role of angiotensin converting enzyme 2 (ACE2) in SARS coronavirus-induced lung injury. Nat. Med. 11:875-879, 2005.

${ }^{127}$ Kuhrt, K., J. McMicking, S. Nanda, C. Nelson-Piercy, and A. Shennan. Placental abruption in a twin pregnancy at 32 weeks' gestation complicated by COVID-19, without vertical transmission to the babies. Am. J. Obstet. Gynecol. MFM 2020. https://doi.org/10.1016/j.ajogmf.2020.100135.

${ }^{128}$ Kushimoto, S., Y. Taira, Y. Kitazawa, K. Okuchi, T. Sakamoto, H. Ishikura, T. Endo, S. Yamanouchi, T. Tagami, J. Yamaguchi, K. Yoshikawa, M. Sugita, Y. Kase, T. Kanemura, H. Takahashi, Y. Kuroki, H. Izumino, H. Rinka, R. Seo, M. Takatori, T. Kaneko, T. Nakamura, T. Irahara, N. Saito, A. Watanabe, and PiCCO Pulmonary Edema Study Group. The clinical usefulness of extravascular lung water and pulmonary vascular permeability index to diagnose and characterize pulmonary edema: a prospective multicenter study on the quantitative differential diagnostic definition for acute lung injury/acute respiratory distress syndrome. Crit Care 16:R232, 2012.

${ }^{129}$ Lai, S. K., Y.-Y. Wang, D. Wirtz, and J. Hanes. Microand macrorheology of mucus. Adv. Drug Deliv. Rev. 61:86-100, 2009.

${ }^{130}$ Lambert, D. W., L. A. Lambert, N. E. Clarke, N. M. Hooper, K. E. Porter, and A. J. Turner. Angiotensinconverting enzyme 2 is subject to post-transcriptional regulation by miR-421. Clin Sci (Lond) 127:243-249, 2014.

${ }^{131}$ Lamers, M. M., J. Beumer, J. van der Vaart, K. Knoops, J. Puschhof, T. I. Breugem, R. B. G. Ravelli, J. P. van Schayck, A. Z. Mykytyn, H. Q. Duimel, E. van Donselaar, S. Riesebosch, H. J. H. Kuijpers, D. Schippers, W. J. van de Wetering, M. de Graaf, M. Koopmans, E. Cuppen, P. J. Peters, B. L. Haagmans, and H. Clevers. SARS-CoV-2 productively infects human gut enterocytes. Science 2020. https://doi.org/10.1126/science.abc1669.

${ }^{132}$ Lamouroux, A., T. Attie-Bitach, J. Martinovic, M. Leruez-Ville, and Y. Ville. Evidence for and against vertical transmission for SARS-CoV-2 (COVID-19). Am. J. Obstet. Gynecol. 2020. https://doi.org/10.1016/j.ajog.2020.04. 039.

${ }^{133}$ Laridan, E., K. Martinod, and S. F. De Meyer. Neutrophil extracellular traps in arterial and venous thrombosis. Semin. Thromb. Hemost. 45:86-93, 2019.

${ }^{134}$ Lee, B. W., H. K. Yap, F. T. Chew, T. C. Quah, K. Prabhakaran, G. S. Chan, S. C. Wong, and C. C. Seah. Age- and sex-related changes in lymphocyte subpopulations of healthy Asian subjects: from birth to adulthood. Cytometry 26:8-15, 1996.

${ }^{135}$ Lester, S. N., and K. Li. Toll-like receptors in antiviral innate immunity. J. Mol. Biol. 426:1246-1264, 2014.

${ }^{136} \mathrm{Li}$, M., L. Chen, J. Zhang, C. Xiong, and X. Li. The SARS-CoV-2 receptor ACE2 expression of maternal-fetal interface and fetal organs by single-cell transcriptome study. PLOS ONE 15:e0230295, 2020.

${ }^{137}$ Li, G., Y. Fan, Y. Lai, T. Han, Z. Li, P. Zhou, P. Pan, W. Wang, D. Hu, X. Liu, Q. Zhang, and J. Wu. Coronavirus infections and immune responses. J. Med. Virol. 92:424432, 2020.

${ }^{138}$ Li, X., M. Geng, Y. Peng, L. Meng, and S. Lu. Molecular immune pathogenesis and diagnosis of COVID-19. $J$. Pharm. Anal. 2020. https://doi.org/10.1016/j.jpha.2020.03. 001 .

${ }^{139}$ Li, X., M. Molina-Molina, A. Abdul-Hafez, V. Uhal, A. Xaubet, and B. D. Uhal. Angiotensin converting enzyme-2 is protective but downregulated in human and experimental lung fibrosis. Am. J. Physiol. Lung Cell. Mol. Physiol. 2008. https://doi.org/10.1152/ajplung.00009.2008.

${ }^{140}$ Li, Z., W. Su, Y. Zhu, T. Tao, D. Li, X. Peng, and J. Qin. Drug absorption related nephrotoxicity assessment on an intestine-kidney chip. Biomicrofluidics 11:034114, 2017. 
${ }^{141}$ Li, R., Y. Wang, R. Chen, W. Gu, L. Zhang, J. Gu, Z. Wang, Y. Liu, Q. Sun, K. Zhang, and C. Liu. Ambient fine particulate matter disrupts hepatic circadian oscillation and lipid metabolism in a mouse model. Environ. Pollut. 262:114179, 2020.

${ }^{142} \mathrm{Li}, \mathrm{H}$., C. Wang, J. Hu, and J. Tan. A study on circadian rhythm disorder of rat lung tissue caused by mechanical ventilation induced lung injury. Int. Immunopharmacol. 18:249-254, 2014.

${ }^{143}$ Liu, Y., W. Sun, J. Li, L. Chen, Y. Wang, L. Zhang, and L. Yu. Clinical features and progression of acute respiratory distress syndrome in coronavirus disease 2019. medRxiv 2020. https://doi.org/10.1101/2020.02.17.200241 66.

${ }^{144}$ Liu, L., Q. Wei, Q. Lin, J. Fang, H. Wang, H. Kwok, H. Tang, K. Nishiura, J. Peng, Z. Tan, T. Wu, K.-W. Cheung, K.-H. Chan, X. Alvarez, C. Qin, A. Lackner, S. Perlman, K.-Y. Yuen, and Z. Chen. Anti-spike IgG causes severe acute lung injury by skewing macrophage responses during acute SARS-CoV infection. JCI Insight 2019. htt ps://doi.org/10.1172/jci.insight.123158.

${ }^{145}$ Liu, T., L. Zhang, D. Joo, and S.-C. Sun. NF- $\kappa$ B signaling in inflammation. Signal Transduct. Target Ther. 2:1-9, 2017.

${ }^{146}$ Liu, D., J.-L. Zhou, F. Hong, and Y.-Q. Zhang. Lung inflammation caused by long-term exposure to titanium dioxide in mice involving in NF- $\kappa \mathrm{B}$ signaling pathway. $J$. Biomed. Mater. Res., Part A 105:720-727, 2017.

${ }^{147}$ Lock, J. Y., T. Carlson, and R. L. Carrier. Mucus models to evaluate the diffusion of drugs and particles. Adv. Drug Deliv. Rev. 124:34-49, 2018.

${ }^{148}$ Loo, Y.-M., and M. Gale. Immune signaling by RIG-Ilike receptors. Immunity 34:680-692, 2011.

${ }^{149} \mathrm{Lu}$, D., and A. J. Hickey. Pulmonary vaccine delivery. Expert Rev. Vaccines 6:213-226, 2007.

${ }^{150} \mathrm{Lu}, \mathrm{R}$., et al. Genomic characterisation and epidemiology of 2019 novel coronavirus: implications for virus origins and receptor binding. Lancet 395:565-574, 2020.

${ }^{151}$ Luo, R., L. Cannon, J. Hernandez, M. J. Piovoso, and R. Zurakowski. Controlling the evolution of resistance. $J$. Process Control 21:367-378, 2011.

${ }^{152}$ Luo, R., M. J. Piovoso, J. Martinez-Picado, and R. Zurakowski. HIV model parameter estimates from interruption trial data including drug efficacy and reservoir dynamics. PLoS ONE 7:e40198, 2012.

${ }^{153}$ Lurie, N., M. Saville, R. Hatchett, and J. Halton. Developing Covid-19 Vaccines At Pandemic Speed. N. Engl. J. Med. 382:1969-1973, 2020.

${ }^{154}$ Majumdar, T., J. Dhar, S. Patel, R. Kondratov, and S. Barik. Circadian transcription factor BMAL1 regulates innate immunity against select RNA viruses. Innate Immun 23:147-154, 2017.

${ }^{155}$ Marshall, L. J., W. Oguejiofor, R. S. Willetts, H. R. Griffiths, and A. Devitt. Developing accurate models of the human airways. J. Pharm. Pharmacol. 67:464-472, 2015.

${ }^{156}$ Mazzoccoli, G., M. Vinciguerra, A. Carbone, and A. Relógio. The circadian clock, the immune system, and viral infections: the intricate relationship between biological time and host-virus interaction. Pathogens 9:83, 2020.

${ }^{157}$ McGonagle, D., K. Sharif, A. O'Regan, and C. Bridgewood. The role of Cytokines including interleukin- 6 in COVID-19 induced pneumonia and macrophage activation syndrome-like disease. Autoimmunity Rev. 2020. http s://doi.org/10.1016/j.autrev.2020.102537.
${ }^{158}$ Miao, H., X. Xia, A. S. Perelson, and H. Wu. On identifiability of nonlinear ODE models and applications in viral dynamics. SIAM Rev. 53:3-39, 2011.

${ }^{159}$ Miyashita, L., G. Foley, S. Semple, and J. Grigg. Traffic-derived particulate matter and angiotensin-converting enzyme 2 expression in human airway epithelial cells. bioRxiv 2020. https://doi.org/10.1101/2020.05.15.097501.

${ }^{160}$ Möhlenkamp, S., and H. Thiele. Ventilation of COVID-19 patients in intensive care units. Herz 2020. https://doi.org/ 10.1007/s00059-020-04923-1.

${ }^{161}$ Mondrinos, M. J., Y.-S. Yi, N.-K. Wu, X. Ding, and D. Huh. Native extracellular matrix-derived semipermeable, optically transparent, and inexpensive membrane inserts for microfluidic cell culture. Lab. Chip 17:3146-3158, 2017.

${ }^{162}$ Mong, M. A., J. A. Awkal, and P. E. Marik. Accelerated hyaluronan concentration as the primary driver of morbidity and mortality in high-risk COVID-19 patients: with therapeutic introduction of an oral hyaluronan inhibitor in the prevention of "Induced Hyaluronan Storm" syndrome. medRxiv 2020. https://doi.org/10.1101/2020.04.19. 20071647.

${ }^{163}$ Monteil, V., H. Kwon, P. Prado, A. Hagelkrüys, R. A. Wimmer, M. Stahl, A. Leopoldi, E. Garreta, C. Hurtado del Pozo, F. Prosper, J. P. Romero, G. Wirnsberger, H. Zhang, A. S. Slutsky, R. Conder, N. Montserrat, A. Mirazimi, and J. M. Penninger. Inhibition of SARS-CoV2 infections in engineered human tissues using clinicalgrade soluble human ACE2. Cell 2020. https://doi.org/10. 1016/j.cell.2020.04.004.

${ }^{164}$ Morgan, J. T., J. Shirazi, E. M. Comber, C. Eschenburg, and J. P. Gleghorn. Fabrication of centimeter-scale and geometrically arbitrary vascular networks using in vitro self-assembly. Biomaterials 189:37-47, 2019.

${ }^{165}$ Morgan, J. T., W. G. Stewart, R. A. McKee, and J. P. Gleghorn. The mechanosensitive ion channel TRPV4 is a regulator of lung development and pulmonary vasculature stabilization. Cell. Mol. Bioeng. 11:309-320, 2018.

${ }^{166}$ Myerson, J. W., P. N. Patel, N. Habibi, L. R. Walsh, Y.W. Lee, D. C. Luther, L. T. Ferguson, M. H. Zaleski, M. E. Zamora, O. A. Marcos-Contreras, P. M. Glassman, I. Johnston, E. D. Hood, T. Shuvaeva, J. V. Gregory, R. Y. Kiseleva, J. Nong, K. M. Rubey, C. F. Greineder, S. Mitragotri, G. S. Worthen, V. M. Rotello, J. Lahann, V. R. Muzykantov, and J. S. Brenner. Supramolecular organization predicts protein nanoparticle delivery to neutrophils for acute lung inflammation diagnosis and treatment. bioRxiv 2020. https://doi.org/10.1101/2020.04. 15.037564 .

${ }^{167}$ Nam, H., Y. Choi, and J. Jang. Vascularized lower respiratory-physiology-on-a-chip. Appl. Sci. 10:900, 2020.

${ }^{168}$ Nelson, C. M., J. P. Gleghorn, M.-F. Pang, J. M. Jaslove, K. Goodwin, V. D. Varner, E. Miller, D. C. Radisky, and H. A. Stone. Microfluidic chest cavities reveal that transmural pressure controls the rate of lung development. Development 144:4328-4335, 2017.

${ }^{169}$ Neutra, M. R., and P. A. Kozlowski. Mucosal vaccines: the promise and the challenge. Nat. Rev. Immunol. 6:148$158,2006$.

${ }^{170}$ Newman, S. P., and H.-K. Chan. In vitro/in vivo comparisons in pulmonary drug delivery. J. Aerosol. Med. Pulm. Drug Deliv. 21:77-84, 2008.

${ }^{171}$ Nieskens, T. T. G., and M. J. Wilmer. Kidney-on-a-chip technology for renal proximal tubule tissue reconstruction. Eur. J. Pharmacol. 790:46-56, 2016. 
${ }^{172}$ Oberfeld, B., A. Achanta, K. Carpenter, P. Chen, N. M. Gilette, P. Langat, J. T. Said, A. E. Schiff, A. S. Zhou, A. K. Barczak, and S. Pillai. SnapShot: COVID-19. Cell 181:954-954.e1, 2020.

${ }^{173}$ Osuna, C. E., S.-Y. Lim, C. Deleage, B. D. Griffin, D. Stein, L. T. Schroeder, R. W. Omange, K. Best, M. Luo, P. T. Hraber, H. Andersen-Elyard, E. F. C. Ojeda, S. Huang, D. L. Vanlandingham, S. Higgs, A. S. Perelson, J. D. Estes, D. Safronetz, M. G. Lewis, and J. B. Whitney. Zika viral dynamics and shedding in rhesus and cynomolgus macaques. Nat. Med. 22:1448-1455, 2016.

${ }^{174}$ Oudit, G. Y., Z. Kassiri, C. Jiang, P. P. Liu, S. M. Poutanen, J. M. Penninger, and J. Butany. SARS-coronavirus modulation of myocardial ACE2 expression and inflammation in patients with SARS. Eur. J. Clin. Investig. 39:618-625, 2009.

${ }^{175}$ Papayannopoulos, V. Neutrophil extracellular traps in immunity and disease. Nat. Rev. Immunol. 18:134-147, 2018.

${ }^{176}$ Park, H.-J., and J.-M. Choi. Sex-specific regulation of immune responses by PPARs. Exp. Mol. Med. 49:e364, 2017.

${ }^{177}$ Park, H.-J., H.-S. Park, J.-U. Lee, A. L. M. Bothwell, and J.-M. Choi. Gender-specific differences in PPAR $\gamma$ regulation of follicular helper T cell responses with estrogen. Sci. Rep. 6:28495, 2016.

${ }^{178}$ Park, H.-J., H.-S. Park, J.-U. Lee, A. L. M. Bothwell, and J.-M. Choi. Sex-based selectivity of $\operatorname{PPAR} \gamma$ regulation in Th1, Th2, and Th17 differentiation. Int. J. Mol. Sci. 2016. https://doi.org/10.3390/ijms17081347.

${ }^{179}$ Park, E.-J., J. Roh, Y. Kim, K. Park, D.-S. Kim, and S.D. Yu. PM 2.5 collected in a residential area induced Th1type inflammatory responses with oxidative stress in mice. Environ. Res. 111:348-355, 2011.

${ }^{180}$ Park, Y. K., T.-Y. Tu, S. H. Lim, I. J. M. Clement, S. Y. Yang, and R. D. Kamm. In vitro microvessel growth and remodeling within a three-dimensional microfluidic environment. Cell. Mol. Bioeng. 7:15-25, 2014.

${ }^{181}$ Patanè, L., D. Morotti, M. R. Giunta, C. Sigismondi, M. G. Piccoli, L. Frigerio, G. Mangili, M. Arosio, and G. Cornolti. Vertical transmission of COVID-19: SARSCoV-2 RNA on the fetal side of the placenta in pregnancies with COVID-19 positive mothers and neonates at birth. Am. J. Obstet. Gynecol. MFM 2020. https://doi.org/ 10.1016/j.ajogmf.2020.100145.

${ }^{182}$ Patil, H. P., D. Freches, L. Karmani, G. A. Duncan, B. Ucakar, J. S. Suk, J. Hanes, B. Gallez, and R. Vanbever. Fate of PEGylated antibody fragments following delivery to the lungs: influence of delivery site, PEG size and lung inflammation. J. Control. Release 272:62-71, 2018.

${ }^{183}$ Paur, H.-R., F. R. Cassee, J. Teeguarden, H. Fissan, S. Diabate, M. Aufderheide, W. G. Kreyling, O. Hänninen, G. Kasper, M. Riediker, B. Rothen-Rutishauser, and O. Schmid. In-vitro cell exposure studies for the assessment of nanoparticle toxicity in the lung - a dialog between aerosol science and biology. J. Aerosol Sci. 42:668-692, 2011.

${ }^{184}$ Pedersen, K. B., K. H. Chhabra, V. K. Nguyen, H. Xia, and E. Lazartigues. The transcription factor HNF1 $\alpha$ induces expression of angiotensin-converting enzyme 2 (ACE2) in pancreatic islets from evolutionarily conserved promoter motifs. Biochim. Biophys. Acta 1225-1235:2013, 1829.

${ }^{185}$ Penfield, C. A., S. G. Brubaker, M. A. Limaye, J. Lighter, A. J. Ratner, K. M. Thomas, J. Meyer, and A. S. Roman. Detection of SARS-COV-2 in placental and fetal mem- brane samples. Am. J. Obstet. Gynecol. MFM 2020. http s://doi.org/10.1016/j.ajogmf.2020.100133.

${ }^{186}$ Perinel, S., M. Launay, E. Botelho-Nevers, É. Diconne, A. Louf-Durier, R. Lachand, M. Murgier, D. Page, R. Vermesch, G. Thierry, and X. Delavenne. towards optimization of hydroxychloroquine dosing in intensive care unit COVID-19 patients. Clin. Infect. Dis. 2020. https://doi.or $\mathrm{g} / 10.1093 / \mathrm{cid} / \mathrm{ciaa394}$.

${ }^{187}$ Perlman, S., and A. A. Dandekar. Immunopathogenesis of coronavirus infections: implications for SARS. Nat. Rev. Immunol. 5:917-927, 2005.

${ }^{188}$ Petersen, T. H., E. A. Calle, L. Zhao, E. J. Lee, L. Gui, M. B. Raredon, K. Gavrilov, T. Yi, Z. W. Zhuang, C. Breuer, E. Herzog, and L. E. Niklason. Tissue-engineered lungs for in vivo implantation. Science 329:538-541, 2010.

${ }^{189}$ Petrovsky, N. Temporal regulation of the human immune system. Expert Rev. Clin. Immunol. 1:379-383, 2005.

${ }^{190}$ Pierce-Williams, R. A. M., J. Burd, L. Felder, R. Khoury, P. S. Bernstein, K. Avila, C. A. Penfield, A. S. Roman, C. A. DeBolt, J. L. Stone, A. Bianco, A. R. Kern-Goldberger, A. Hirshberg, S. K. Srinivas, J. S. Jayakumaran, J. S. Brandt, H. Anastasio, M. Birsner, D. S. O'Brien, H. M. Sedev, C. D. Dolin, W. T. Schnettler, A. Suhag, S. Ahluwalia, R. S. Navathe, A. Khalifeh, K. Anderson, and V. Berghella. Clinical course of severe and critical COVID-19 in hospitalized pregnancies: a US cohort study. Am. J. Obstet. Gynecol. MFM 2020. https://doi.org/10.1016/j.ajo gmf.2020.100134.

${ }^{191}$ Polini, A., L. L. del Mercato, A. Barra, Y. S. Zhang, F. Calabi, and G. Gigli. Towards the development of human immune-system-on-a-chip platforms. Drug Discov. Today 24:517-525, 2019.

${ }^{192}$ Prompetchara, E., C. Ketloy, and T. Palaga. Immune responses in COVID-19 and potential vaccines: lessons learned from SARS and MERS epidemic. Asian Pac. J. Allergy Immunol. 38:1-9, 2020.

${ }^{193}$ Protano, C., P. Avino, M. Manigrasso, V. Vivaldi, F. Perna, F. Valeriani, and M. Vitali. Environmental electronic vape exposure from four different generations of electronic cigarettes: airborne particulate matter levels. Int. J. Environ. Res. Public Health 2018. https://doi.org/10. 3390/ijerph15102172.

${ }^{194}$ Qin, C., L. Zhou, Z. Hu, S. Zhang, S. Yang, Y. Tao, C. Xie, K. Ma, K. Shang, W. Wang, and D.-S. Tian. Dysregulation of immune response in patients with coronavirus (COVID-19) in Wuhan, China. Clin. Infect. Dis. 2019. https://doi.org/10.1093/cid/ciaa248.

${ }^{195}$ Radzikowska, U., M. Ding, G. Tan, D. Zhakparov, Y. Peng, P. Wawrzyniak, M. Wang, S. Li, H. Morita, C. Altunbulakli, M. Reiger, A. Neumann, N. Lunjani, C. Traidl-Hoffmann, K. Nadeau, L. O’Mahony, C. Akdis, and M. Sokolowska. Distribution of ACE2, CD147, cyclophilins, CD26 and other SARS-CoV-2 associated molecules in human tissues and immune cells in health and disease. bioRxiv 2020. https://doi.org/10.1101/2020.05.14. 090332.

${ }^{196}$ Ross, A. E., M. C. Belanger, J. F. Woodroof, and R. R. Pompano. Spatially resolved microfluidic stimulation of lymphoid tissue ex vivo. Analyst 142:649-659, 2017.

${ }^{197}$ Ross, A. E., and R. R. Pompano. Diffusion of cytokines in live lymph node tissue using microfluidic integrated optical imaging. Anal. Chim. Acta 1000:205-213, 2018.

${ }^{198}$ Saito, E., R. Kuo, R. M. Pearson, N. Gohel, B. Cheung, N. J. C. King, S. D. Miller, and L. D. Shea. Designing drug-free biodegradable nanoparticles to modulate 
inflammatory monocytes and neutrophils for ameliorating inflammation. J. Control. Release 300:185-196, 2019.

${ }^{199}$ Sankaran-Walters, S., M. Macal, I. Grishina, L. Nagy, L. Goulart, K. Coolidge, J. Li, A. Fenton, T. Williams, M. K. Miller, J. Flamm, T. Prindiville, M. George, and S. Dandekar. Sex differences matter in the gut: effect on mucosal immune activation and inflammation. Biol. Sex Differ. 4:10, 2013.

${ }^{200}$ Schappell, L. E., D. J. Minahan, and J. Gleghorn. A microfluidic system to measure neonatal lung compliance over late stage development as a functional measure of lung tissue mechanics. J. Biomech. Eng. 2020. https://doi. org/10.1115/1.4047133.

${ }^{201}$ Scheff, J. D., S. E. Calvano, S. F. Lowry, and I. P. Androulakis. Modeling the influence of circadian rhythms on the acute inflammatory response. J. Theor. Biol. 264:10681076, 2010.

${ }^{202}$ Scotland, R. S., M. J. Stables, S. Madalli, P. Watson, and D. W. Gilroy. Sex-differences in resident immune cell phenotype underlies more efficient acute inflammatory responses in female mice. Blood 118:5918-5927, 2011.

${ }^{203}$ Senkel, S., B. Lucas, L. Klein-Hitpass, and G. U. Ryffel. Identification of target genes of the transcription factor HNF $1 \beta$ and HNF $1 \alpha$ in a human embryonic kidney cell line. Biochim. Biophys. Acta (BBA) Gene Struct. Expr. 1731:179-190, 2005.

${ }^{204}$ Shadan, F. F. A circadian model for viral persistence. Med. Hypoth. 68:546-553, 2007.

${ }^{205}$ Shanes, E. D., L. B. Mithal, S. Otero, H. A. Azad, E. S. Miller, and J. A. Goldstein. Placental pathology in COVID-19. medRxiv 2020. https://doi.org/10.1101/2020.0 5.08.20093229.

${ }^{206}$ Shang, J., Y. Wan, C. Luo, G. Ye, Q. Geng, A. Auerbach, and F. Li. Cell entry mechanisms of SARS-CoV-2. Proc. Natl. Acad. Sci. 117:11727-11734, 2020.

${ }^{207}$ Sharma, S., I. Singh, S. Haider, M. Z. Malik, K. Ponnusamy, and E. Rai. ACE2 homo-dimerization, human genomic variants and interaction of host proteins explain high population specific differences in outcomes of COVID19. bioRxiv 2020. https://doi.org/10.1101/2020.04.24.0 50534.

${ }^{208}$ Shi, Y., Y. Wang, C. Shao, J. Huang, J. Gan, X. Huang, E. Bucci, M. Piacentini, G. Ippolito, and G. Melino. COVID-19 infection: the perspectives on immune responses. Cell Death Differ. 2020. https://doi.org/10.103 8/s41418-020-0530-3.

${ }^{209}$ Shirazi, J., J. T. Morgan, E. M. Comber, and J. P. Gleghorn. Generation and morphological quantification of large scale, three-dimensional, self-assembled vascular networks. MethodsX 6:1907-1918, 2019.

${ }^{210}$ Silver, A. C., A. Arjona, W. E. Walker, and E. Fikrig. The Circadian Clock Controls toll-like receptor 9-mediated innate and adaptive immunity. Immunity 36:251-261, 2012.

${ }^{211}$ Slutsky, A. S., and V. M. Ranieri. Ventilator-Induced Lung Injury. N. Engl. J. Med. 369:2126-2136, 2013.

${ }^{212}$ Smith, S. E. P., J. Li, K. Garbett, K. Mirnics, and P. H. Patterson. Maternal immune activation alters fetal brain development through interleukin-6. J. Neurosci. 27:1069510702, 2007.

${ }^{213}$ Smithmyer, M. E., S. E. Cassel, and A. M. Kloxin. Bridging 2D and 3D culture: probing impact of extracellular environment on fibroblast activation in layered hydrogels. AIChE J. 65:e16837, 2019.
${ }^{214}$ Solt, L. A., N. Kumar, P. Nuhant, Y. Wang, J. L. Lauer, J. Liu, M. A. Istrate, T. M. Kamenecka, W. R. Roush, D. Vidović, S. C. Schürer, J. Xu, G. Wagoner, P. D. Drew, P. R. Griffin, and T. P. Burris. Suppression of T H 17 differentiation and autoimmunity by a synthetic ROR ligand. Nature 472:491-494, 2011.

${ }^{215}$ Steinman, R. M., and H. Hemmi. Dendritic cells: translating innate to adaptive immunity. In: From Innate Immunity to Immunological Memory, edited by $\mathrm{B}$. Pulendran, and R. Ahmed. Berlin, Heidelberg: Springer, 2006, pp. 17-58. https://doi.org/10.1007/3-540-32636-7_2.

${ }^{216}$ Stengel, R. F. Mutation and control of the human immunodeficiency virus. Math. Biosci. 213:93-102, 2008.

${ }^{217}$ Su, H., M. Yang, C. Wan, L.-X. Yi, F. Tang, H.-Y. Zhu, F. Yi, H.-C. Yang, A. B. Fogo, X. Nie, and C. Zhang. Renal histopathological analysis of 26 postmortem findings of patients with COVID-19 in China. Kidney Int. 2020. https://doi.org/10.1016/j.kint.2020.04.003.

${ }^{218}$ Sul, B., Z. Oppito, S. Jayasekera, B. Vanger, A. Zeller, M. Morris, K. Ruppert, T. Altes, V. Rakesh, S. Day, R. Robinson, J. Reifman, and A. Wallqvist. Assessing airflow sensitivity to healthy and diseased lung conditions in a computational fluid dynamics model validated in vitro. $J$. Biomech. Eng. 2018. https://doi.org/10.1115/1.4038896.

${ }^{219}$ Sundar, I. K., K. Rashid, M. T. Sellix, and I. Rahman. The nuclear receptor and clock gene REV-ERB $\alpha$ regulates cigarette smoke-induced lung inflammation. Biochem. Biophys. Res. Commun. 493:1390-1395, 2017.

${ }^{220}$ Sundar, I. K., H. Yao, M. T. Sellix, and I. Rahman. Circadian molecular clock in lung pathophysiology. Am. J. Physiol. Lung Cell. Mol. Physiol. 309:L1056-L1075, 2015.

${ }^{221}$ Sungnak, W., N. Huang, C. Bécavin, M. Berg, R. Queen, M. Litvinukova, C. Talavera-López, H. Maatz, D. Reichart, F. Sampaziotis, K. B. Worlock, M. Yoshida, and J. L. Barnes. SARS-CoV-2 entry factors are highly expressed in nasal epithelial cells together with innate immune genes. Nat. Med. 26:681-687, 2020.

${ }^{222}$ Suwa, T., J. C. Hogg, K. B. Quinlan, A. Ohgami, R. Vincent, and S. F. van Eeden. Particulate air pollution induces progression of atherosclerosis. J. Am. Coll. Cardiol. 39:935-942, 2002.

${ }^{223}$ Tam, A., D. Morrish, S. Wadsworth, D. Dorscheid, S. P. Man, and D. D. Sin. The role of female hormones on lung function in chronic lung diseases. BMC Womens Health 11:24, 2011.

${ }^{224}$ Tan, L., Q. Wang, D. Zhang, J. Ding, Q. Huang, Y.-Q. Tang, Q. Wang, and H. Miao. Lymphopenia predicts disease severity of COVID-19: a descriptive and predictive study. Signal Transduct. Targeted Ther. 5:1-3, 2020.

${ }^{225}$ Tang, A., Z.-D. Tong, H.-L. Wang, Y.-X. Dai, K.-F. Li, J.-N. Liu, W.-J. Wu, C. Yuan, M.-L. Yu, P. Li, and J.-B. Yan. Detection of novel coronavirus by RT-PCR in stool specimen from asymptomatic child. China. Emerg. Infect. Dis. 26:1337-1339, 2020.

${ }^{226}$ Tenenbaum-Katan, J., A. Artzy-Schnirman, R. Fishler, N. Korin, and J. Sznitman. Biomimetics of the pulmonary environment in vitro: a microfluidics perspective. Biomicrofluidics 12:042209, 2018.

${ }^{227}$ Teuwen, L.-A., V. Geldhof, A. Pasut, and P. Carmeliet. COVID-19: the vasculature unleashed. Nat. Rev. Immunol. 2020. https://doi.org/10.1038/s41577-020-0343-0.

${ }^{228}$ Tikellis, C., and M. C. Thomas. Angiotensin-converting enzyme 2 (ACE2) is a key modulator of the renin angio- 
tensin system in health and disease. Int. J. Peptides 2012. h ttps://doi.org/10.1155/2012/256294.

${ }^{229}$ Tipnis, S. R., N. M. Hooper, R. Hyde, E. Karran, G. Christie, and A. J. Turner. A human homolog of angiotensin-converting enzyme: cloning and functional expression as a captopril-insensitive carboxypeptidase. J. Biol. Chem. 275:33238-33243, 2000.

${ }^{230}$ Umbrello, M., P. Formenti, L. Bolgiaghi, and D. Chiumello. Current concepts of ARDS: a narrative review. Int. J. Mol. Sci. 2016. https://doi.org/10.3390/ijm s18010064.

${ }^{231}$ Unger, T., U. M. Steckelings, and V. J. Dzau. The Protective Arm of the Renin Angiotensin System (RAS). New York: Elsevier, 2015. https://doi.org/10.1016/C2013-0-23 135-4.

${ }^{232}$ Valdés, G., L. A. A. Neves, L. Anton, J. Corthorn, C. Chacón, A. M. Germain, D. C. Merrill, C. M. Ferrario, R. Sarao, J. Penninger, and K. B. Brosnihan. Distribution of angiotensin-(1-7) and ACE2 in human placentas of normal and pathological pregnancies. Placenta 27:200-207, 2006.

${ }^{233}$ van Eeden, S. F., and J. C. Hogg. Systemic inflammatory response induced by particulate matter air pollution: the importance of bone-marrow stimulation. J. Toxicol. Environ. Health Part A 65:1597-1613, 2002.

${ }^{234}$ Varga, Z., A. J. Flammer, P. Steiger, M. Haberecker, R. Andermatt, A. S. Zinkernagel, M. R. Mehra, R. A. Schuepbach, F. Ruschitzka, and H. Moch. Endothelial cell infection and endotheliitis in COVID-19. Lancet 395:1417-1418, 2020.

${ }^{235}$ Verbanck, S., G. Ghorbaniasl, M. F. Biddiscombe, D. Dragojlovic, N. Ricks, C. Lacor, B. Ilsen, J. de Mey, D. Schuermans, S. R. Underwood, P. J. Barnes, W. Vincken, and O. S. Usmani. Inhaled aerosol distribution in human airways: a scintigraphy-guided study in a $3 \mathrm{D}$ printed model. J. Aerosol. Med. Pulm. Drug Deliv. 29:525-533, 2016.

${ }^{236}$ Vinciguerra, M., and E. Greco. Sars-CoV-2 and black population: ACE2 as shield or blade? Infect. Genet. Evol. 2020. https://doi.org/10.1016/j.meegid.2020.104361.

${ }^{237}$ Vlahakis, N. E., M. A. Schroeder, A. H. Limper, and R. D. Hubmayr. Stretch induces cytokine release by alveolar epithelial cells in vitro. Am. J. Physiol. Lung Cell. Mol. Physiol. 277:L167-L173, 1999.

${ }^{238}$ Voiriot, G., K. Razazi, V. Amsellem, J. Tran Van Nhieu, S. Abid, S. Adnot, A. Mekontso Dessap, and B. Maitre. Interleukin-6 displays lung anti-inflammatory properties and exerts protective hemodynamic effects in a double-hit murine acute lung injury. Respir. Res. 18:64, 2017.

${ }^{239}$ Vozeh, S., and J. L. Steimer. Feedback control methods for drug dosage optimisation: CONCEPTS, classification and clinical application. Clin. Pharmacokinet. 10:457-476, 1985.

${ }^{240}$ Vukkadala, N., Z. J. Qian, F. C. Holsinger, Z. M. Patel, and E. Rosenthal. COVID-19 and the otolaryngologist: preliminary evidence-based review. Laryngoscope 2020. h ttps://doi.org/10.1002/lary.28672.

${ }^{241}$ Wang, D., B. Hu, C. Hu, F. Zhu, X. Liu, J. Zhang, B. Wang, H. Xiang, Z. Cheng, Y. Xiong, Y. Zhao, Y. Li, X. Wang, and Z. Peng. Clinical Characteristics of 138 hospitalized patients with 2019 novel coronavirus-infected pneumonia in Wuhan, China. JAMA 323:1061-1069, 2020.

${ }^{242}$ Wang, Y., R. Li, R. Chen, W. Gu, L. Zhang, J. Gu, Z. Wang, Y. Liu, Q. Sun, K. Zhang, and C. Liu. Ambient fine particulate matter exposure perturbed circadian rhythm and oscillations of lipid metabolism in adipose tissues. Chemosphere 251:126392, 2020.

${ }^{243}$ Wang, X., D. T. T. Phan, S. C. George, C. C. W. Hughes, and A. P. Lee. Engineering anastomosis between living capillary networks and endothelial cell-lined microfluidic channels. Lab. Chip 16:282-290, 2016.

${ }^{244}$ Wang, Q., I. K. Sundar, D. Li, J. H. Lucas, T. Muthumalage, S. R. McDonough, and I. Rahman. E-cigaretteinduced pulmonary inflammation and dysregulated repair are mediated by $\mathrm{nAChR} \alpha 7$ receptor: role of $\mathrm{nAChR} \alpha 7$ in ACE2 Covid-19 receptor regulation. Respir. Res. 2020. h ttps://doi.org/10.21203/rs.2.23829/v2.

${ }^{245}$ Wang, T., L. Wang, L. Moreno-Vinasco, G. D. Lang, J. H. Siegler, B. Mathew, P. V. Usatyuk, J. M. Samet, A. S. Geyh, P. N. Breysse, V. Natarajan, and J. G. N. Garcia. Particulate matter air pollution disrupts endothelial cell barrier via calpain-mediated tight junction protein degradation. Particle Fibre Toxicol. 9:35, 2012.

${ }^{246}$ Wang, Q., L. Zhang, K. Kuwahara, L. Li, Z. Liu, T. Li, H. Zhu, J. Liu, Y. Xu, J. Xie, H. Morioka, N. Sakaguchi, C. Qin, and G. Liu. Immunodominant SARS coronavirus epitopes in humans elicited both enhancing and neutralizing effects on infection in non-human primates. ACS Infect. Dis. 2:361-376, 2016.

${ }^{247}$ Wei, Y., J. Zhang, Z. Li, A. Gow, K. F. Chung, M. Hu, Z. Sun, L. Zeng, T. Zhu, G. Jia, X. Li, M. Duarte, and X. Tang. Chronic exposure to air pollution particles increases the risk of obesity and metabolic syndrome: findings from a natural experiment in Beijing. FASEB J. 30:2115-2122, 2016.

${ }^{248}$ Williamson, B. N., F. Feldmann, B. Schwarz, K. MeadeWhite, D. P. Porter, J. Schulz, N. van Doremalen, I. Leighton, C. K. Yinda, L. Pérez-Pérez, A. Okumura, J. Lovaglio, P. W. Hanley, G. Saturday, C. M. Bosio, S. Anzick, K. Barbian, T. Cihlar, C. Martens, D. P. Scott, V. J. Munster, and E. de Wit. Clinical benefit of remdesivir in rhesus macaques infected with SARS-CoV-2. Microbiology 2020. https://doi.org/10.1101/2020.04.15.043166.

${ }^{249}$ Wilson, M. R., S. Choudhury, M. E. Goddard, K. P. O'Dea, A. G. Nicholson, and M. Takata. High tidal volume upregulates intrapulmonary cytokines in an in vivo mouse model of ventilator-induced lung injury. J. Appl. Physiol. 95:1385-1393, 2003.

${ }^{250}$ Woodward, N. C., A. L. Crow, Y. Zhang, S. Epstein, J. Hartiala, R. Johnson, H. Kocalis, A. Saffari, I. Sankaranarayanan, O. Akbari, G. Ramanathan, J. A. Araujo, C. E. Finch, S. G. Bouret, C. Sioutas, T. E. Morgan, and H. Allayee. Exposure to nanoscale particulate matter from gestation to adulthood impairs metabolic homeostasis in mice. Sci. Rep. 9:1-11, 2019.

${ }^{251}$ Wösten-Van Asperen, R. M., R. Lutter, P. A. Specht, G. N. Moll, J. B. Van Woensel, C. M. Van Der Loos, H. Van Goor, J. Kamilic, S. Florquin, and A. P. Bos. Acute respiratory distress syndrome leads to reduced ratio of ACE/ ACE2 activities and is prevented by angiotensin-(17) or an angiotensin II receptor antagonist. J. Pathol. 225:618-627, 2011.

${ }^{252} \mathrm{Wu}, \mathrm{Y}$. Compensation of ACE2 Function for Possible Clinical Management of 2019-nCoV-induced acute lung injury. Virol. Sin. 12250:2019-2021, 2020.

${ }^{253}$ Wu, X., R. C. Nethery, B. M. Sabath, D. Braun, and F. Dominici. Exposure to air pollution and COVID-19 mortality in the United States: a nationwide cross-sectional study. MedRxiv 2020. https://doi.org/10.1101/2020. 04.05.20054502. 
${ }^{254}$ Wu, Y., X. Xu, Z. Chen, J. Duan, K. Hashimoto, L. Yang, C. Liu, and C. Yang. Nervous system involvement after infection with COVID-19 and other coronaviruses. Brain Behav. Immun. 2020. https://doi.org/10.1016/j.bbi. 2020.03.031.

${ }^{255} \mathrm{Wu}$, D., and X. O. Yang. TH17 responses in cytokine storm of COVID-19: An emerging target of JAK2 inhibitor Fedratinib. J. Microbiol. Immunol. Infect. 2020. h ttps://doi.org/10.1016/j.jmii.2020.03.005.

${ }^{256} \mathrm{Wu}$, F., S. Zhao, B. Yu, Y.-M. Chen, W. Wang, Z.-G. Song, Y. Hu, Z.-W. Tao, J.-H. Tian, Y.-Y. Pei, M.-L. Yuan, Y.-L. Zhang, F.-H. Dai, Y. Liu, Q.-M. Wang, J.-J. Zheng, L. Xu, E. C. Holmes, and Y.-Z. Zhang. A new coronavirus associated with human respiratory disease in China. Nature 579:265-269, 2020.

${ }^{257}$ Xie, J., Z. Tong, X. Guan, B. Du, and H. Qiu. Clinical characteristics of patients who died of coronavirus disease 2019 in China. JAMA Netw. Open 3:e205619-e205619, 2020.

${ }^{258}$ Xu, Z., L. Shi, Y. Wang, J. Zhang, L. Huang, C. Zhang, S. Liu, P. Zhao, H. Liu, L. Zhu, Y. Tai, C. Bai, T. Gao, J. Song, P. Xia, J. Dong, J. Zhao, and F.-S. Wang. Pathological findings of COVID-19 associated with acute respiratory distress syndrome. Lancet Respir. Med. 8:420422, 2020.

${ }^{259}$ Yang, A.-P., J. Liu, W. Tao, and H. Li. The diagnostic and predictive role of NLR, d-NLR and PLR in COVID19 patients. Int. Immunopharmacol. 2020. https://doi.org/ 10.1016/j.intimp.2020.106504.

${ }^{260}$ Yang, X. Y., L. H. Wang, T. Chen, D. R. Hodge, J. H. Resau, L. DaSilva, and W. L. Farrar. Activation of human $\mathrm{T}$ lymphocytes is inhibited by peroxisome proliferator-activated receptor gamma (PPARgamma) agonists. PPARgamma co-association with transcription factor NFAT. J. Biol. Chem. 275:4541-4544, 2000.

${ }^{261}$ Yang, P.-L., T. M. Ward, R. L. Burr, V. K. Kapur, S. M. McCurry, M. V. Vitiello, C. L. Hough, and E. C. Parsons. Sleep and Circadian Rhythms In Survivors Of Acute Respiratory Failure. Front Neurol 2020. https://doi.org/10. 3389/fneur.2020.0009.

${ }^{262}$ Yao, H., I. K. Sundar, Y. Huang, J. Gerloff, M. T. Sellix, P. J. Sime, and I. Rahman. Disruption of sirtuin 1-mediated control of circadian molecular clock and inflammation in chronic obstructive pulmonary disease. Am. $J$. Respir. Cell Mol. Biol. 53:782-792, 2015.

${ }^{263}$ Ye, Z., Y. Zhang, Y. Wang, Z. Huang, and B. Song. Chest $\mathrm{Ct}$ manifestations of new coronavirus disease 2019 (COVID-19): a pictorial review. Eur. Radiol. 2019. http s://doi.org/10.1007/s00330-020-06801-0.

${ }^{264}$ Yilla, M., B. H. Harcourt, C. J. Hickman, M. McGrew, A. Tamin, C. S. Goldsmith, W. J. Bellini, and L. J. Anderson. SARS-coronavirus replication in human peripheral monocytes/macrophages. Virus Res. 107:93-101, 2005.

${ }^{265}$ Yiu, H. H., A. L. Graham, and R. F. Stengel. Dynamics of a cytokine storm. PLOS ONE 7:e45027, 2012.

${ }^{266}$ Yockey, L. J., C. Lucas, and A. Iwasaki. Contributions of maternal and fetal antiviral immunity in congenital disease. Science 368:608-612, 2020.

${ }^{267}$ Zeng, H., C. Xu, J. Fan, Y. Tang, Q. Deng, W. Zhang, and $\mathrm{X}$. Long. Antibodies in infants born to mothers with COVID-19 pneumonia. JAMA 323:1848-1849, 2020.

${ }^{268}$ Zhang, Y., C. Coarfa, X. Dong, W. Jiang, B. HaywardPiatkovskyi, J. P. Gleghorn, and K. Lingappan. MicroRNA-30a as a candidate underlying sex-specific differences in neonatal hyperoxic lung injury: implications for
BPD. Am. J. Physiol. Lung Cell Mol. Physiol. 316:L144L156, 2019.

${ }^{269}$ Zhang, Y., X. Dong, J. Shirazi, J. P. Gleghorn, and K. Lingappan. Pulmonary endothelial cells exhibit sexual dimorphism in their response to hyperoxia. Am. J. Physiol. Heart Circul. Physiol. 315:H1287-H1292, 2018.

${ }^{270}$ Zhang, H., Z. Kang, H. Gong, D. Xu, J. Wang, Z. Li, Z. Li, X. Cui, J. Xiao, J. Zhan, T. Meng, W. Zhou, J. Liu, and $\mathrm{H}$. Xu. Digestive system is a potential route of COVID-19: an analysis of single-cell coexpression pattern of key proteins in viral entry process. Gut 69:1010-1018, 2020.

${ }^{271}$ Zhang, M. A., D. Rego, M. Moshkova, H. Kebir, A. Chruscinski, H. Nguyen, R. Akkermann, F. Z. Stanczyk, A. Prat, L. Steinman, and S. E. Dunn. Peroxisome proliferator-activated receptor (PPAR) $\alpha$ and $-\gamma$ regulate IFN $\gamma$ and IL-17A production by human T cells in a sex-specific way. Proc. Natl. Acad. Sci. 109:9505-9510, 2012.

${ }^{272}$ Zhang, T., L. X. Sun, and R. E. Feng. Comparison of clinical and pathological features between severe acute respiratory syndrome and coronavirus disease 2019. Zhonghua Jie He He Hu Xi Za Zhi 43:E040, 2020.

${ }^{273}$ Zhang, R., X. Wang, L. Ni, X. Di, B. Ma, S. Niu, C. Liu, and R. J. Reiter. COVID-19: melatonin as a potential adjuvant treatment. Life Sci. 250:117583, 2020.

${ }^{274}$ Zhang, C., L. Yang, S. Liu, S. Ma, Y. Wang, Z. Cai, H. Du, R. Li, L. Kang, M. Su, J. Zhang, Z. Liu, and B. Zhang. Survey of insomnia and related social psychological factors among medical staff involved in the novel coronavirus disease outbreak. Front. Psychiatry 11:2020, 2019. https://doi.org/10.3389/fpsyt.2020.00306.

${ }^{275}$ Zhang, W., Y. Zhao, F. Zhang, Q. Wang, T. Li, Z. Liu, J. Wang, Y. Qin, X. Zhang, X. Yan, X. Zeng, and S. Zhang. The use of anti-inflammatory drugs in the treatment of people with severe coronavirus disease 2019 (COVID-19): the perspectives of clinical immunologists from China. Clin. Immunol. 214:108393, 2020.

${ }^{276}$ Zhao, M. Cytokine storm and immunomodulatory therapy in COVID-19: role of chloroquine and anti-IL-6 monoclonal antibodies. Int. J. Antimicrob. Agents 2020. h ttps://doi.org/10.1016/j.ijantimicag.2020.105982.

${ }^{277}$ Zhao, Y., Z. Zhao, Y. Wang, Y. Zhou, Y. Ma, and W. Zuo. Single-cell RNA expression profiling of ACE2, the putative receptor of Wuhan 2019-nCov. bioRxiv 2020. h ttps://doi.org/10.1101/2020.01.26.919985.

${ }^{278}$ Zhou, P., X.-L. Yang, X.-G. Wang, B. Hu, L. Zhang, W. Zhang, H.-R. Si, Y. Zhu, B. Li, C.-L. Huang, H.-D. Chen, J. Chen, Y. Luo, H. Guo, R.-D. Jiang, M.-Q. Liu, Y. Chen, X.-R. Shen, X. Wang, X.-S. Zheng, K. Zhao, Q.-J. Chen, F. Deng, L.-L. Liu, B. Yan, F.-X. Zhan, Y.-Y. Wang, G.-F. Xiao, and Z.-L. Shi. A pneumonia outbreak associated with a new coronavirus of probable bat origin. Nature 579:270-273, 2020.

${ }^{279}$ Zhu, Y., J. Xie, F. Huang, and L. Cao. Association between short-term exposure to air pollution and COVID19 infection: evidence from China. Sci. Total Environ. 727:138704, 2020.

${ }^{280}$ Zuo, Y., M. Zuo, S. Yalavarthi, K. Gockman, J. A. Madison, H. Shi, J. S. Knight, and Y. Kanthi. Neutrophil extracellular traps and thrombosis in COVID-19. medRxiv 2020. https://doi.org/10.1101/2020.04.30.200867 36.

${ }^{281}$ Zurakowski, R. Nonlinear observer output-feedback MPC treatment scheduling for HIV. BioMed. Eng. OnLine 10:40, 2011. 
${ }^{282}$ Zurakowski, R. Using the tools we have: low-efficacy vaccines and HIV. EBioMedicine 2:1867-1868, 2015.

${ }^{283}$ Zurakowski, R., and A. R. Teel. A model predictive control based scheduling method for HIV therapy. $J$. Theor. Biol. 238:368-382, 2006.

${ }^{284}$ Zurakowski, R., and D. Wodarz. Model-driven approaches for in vitro combination therapy using
ONYX-015 replicating oncolytic adenovirus. J. Theor. Biol. 245:1-8, 2007.

Publisher's Note Springer Nature remains neutral with regard to jurisdictional claims in published maps and institutional affiliations. 